\title{
Changes in patients' depression and anxiety associated with changes in patient-reported outcomes after spine surgery
}

\author{
Rafa Rahman, BS, ${ }^{1}$ Alvaro Ibaseta, MS, ${ }^{1}$ Jay S. Reidler, MD, MPH, ${ }^{1}$ Nicholas S. Andrade, BS, ${ }^{1}$ \\ Richard L. Skolasky, MA, ScD, ${ }^{1}$ Lee H. Riley III, MD, ${ }^{1}$ David B. Cohen, MD, ${ }^{1}$ Daniel M. Sciubba, MD, ${ }^{2}$ \\ Khaled M. Kebaish, MD, FRCSC, ${ }^{1}$ and Brian J. Neuman, MD
}

Departments of ${ }^{1}$ Orthopaedic Surgery and ${ }^{2}$ Neurosurgery, The Johns Hopkins University School of Medicine, Baltimore, Maryland

OBJECTIVE The authors conducted a study to analyze associations between changes in depression/anxiety before and 12 months after spine surgery, as well as changes in scores using the Patient-Reported Outcomes Measurement Information System (PROMIS) at the same time points.

METHODS Preoperatively and 12 months postoperatively, the authors assessed PROMIS scores for depression, anxiety, pain, physical function, sleep disturbance, and satisfaction with participation in social roles among 206 patients undergoing spine surgery for deformity correction or degenerative disease. Patients were stratified according to preoperative/postoperative changes in depression and anxiety, which were categorized as persistent, improved, newly developed postoperatively, or absent. Multivariate regression was used to control for confounders and to compare changes in patient-reported outcomes (PROs).

RESULTS Fifty patients (24\%) had preoperative depression, which improved in 26 (52\%). Ninety-four patients (46\%) had preoperative anxiety, which improved in 70 (74\%). Household income was the only preoperative characteristic that differed significantly between patients whose depression persisted and those whose depression improved. Compared with the no-depression group, patients with persistent depression had less improvement in all 4 domains, and patients with postoperatively developed depression had less improvement in pain, physical function, and satisfaction with social roles. Compared with the group of patients with postoperatively improved depression, patients with persistent depression had less improvement in pain and physical function, and patients with postoperatively developed depression had less improvement in pain. Compared with patients with no anxiety, those with persistent anxiety had less improvement in physical function, sleep disturbance, and satisfaction with social roles, and patients with postoperatively developed anxiety had less improvement in pain, physical function, and satisfaction with social roles. Compared with patients with postoperatively improved anxiety, patients with persistent anxiety had less improvement in pain, physical function, and satisfaction with social roles, and those with postoperatively developed anxiety had less improvement in pain, physical function, and satisfaction with social roles. All reported differences were significant at $p<0.05$.

CONCLUSIONS Many spine surgery patients experienced postoperative improvements in depression/anxiety. Improvements in 12-month PROs were smaller among patients with persistent or postoperatively developed depression/anxiety compared with patients who had no depression or anxiety before or after surgery and those whose depression/anxiety improved after surgery. Postoperative changes in depression/anxiety may have a greater effect than preoperative depression/anxiety on changes in PROs after spine surgery. Addressing the mental health of spine surgery patients may improve postoperative PROs.

- CLASSIFICATION OF EVIDENCE Type of question: causation; study design: prospective cohort study; evidence: class III. https://thejns.org/doi/abs/10.3171/2019.11.SPINE19586

KEYWORDS anxiety; degenerative spine disease; depression; patient-reported outcomes; Patient-Reported Outcomes Measurement Information System; PROMIS; spine deformity

ABBREVIATIONS LOS = length of stay; PRO = patient-reported outcome; PROMIS = Patient-Reported Outcomes Measurement Information System.

SUBMITTED May 14, 2019. ACCEPTED November 6, 2019.

INCLUDE WHEN CITING Published online January 31, 2020; DOI: 10.3171/2019.11.SPINE19586. 


\section{- CLASSIFICATION OF EVIDENCE}

Type of Question Causation

Study Design Prospective Cohort Study

Evidence Class III

Summary Statement

This class III study provides evidence of an association between postoperatively improved or absent depression or anxiety and patient satisfaction in adults undergoing surgery for cervical and lumbar degenerative or deformity disorders, but it does not establish a causal relationship.

\section{Classification of Evidence}

Rahman and colleagues have tackled an important question for spine surgeons with energy and statistical sophistication. The authors ask whether depression or anxiety that persists or worsens from the preoperative to the 12-month postoperative period results in worse patient-reported outcomes (pain interference, physical function, sleep disturbance, and social satisfaction). They collect their data using the Patient-Reported Outcomes Measurement Information System (PROMIS). Theirs is a question of "causation" (the other three questions typically encountered in the medical literature are: therapeutic, diagnostic, and prognostic), and Rahman et al. have used a prospective cohort trial design to test their hypothesis. This is the optimum study design for questions of causation, which can't be addressed by randomized controlled trials. Depending on its features, such a study can range from class I to class IV in level of evidence. The current study raises several concerns, which lead to a class III designation. First, while multivariate analysis was used to account for potential confounders in their data, the authors impose the unconventional restriction that a variable must be both statistically significantly different between groups and must be statistically significantly associated with their outcome of interest in order to be included in the multivariate model. Typically, either criterion alone would suffice. In addition, while patients do not know their scores on the various testing batteries they complete, they are not masked to either the "exposure" (pre- to postoperative change in their depression or anxiety) or the "outcome" (satisfaction). Most importantly, two critical components of Hill's criteria for demonstrating a causal relationship (temporality and biologic plausibility) are not fulfilled. Because the exposure (at least one component of it) is measured at the same time as the outcome, the temporal relationship between exposure and outcome is not clear. And because either direction of the effect (depression/ anxiety causes reduced satisfaction or reduced satisfaction causes depression/anxiety) makes sense, the requirement for biological plausibility is not fulfilled. Finally, even if a causal link were to be established, only an intervention study could test the authors' assertion that "addressing the mental health of spine surgery patients may improve postoperative PROs." One further observation: the authors collected their data using patient surveys and report a $40 \%$ survey response. While this is a very respectable response rate, it means that $60 \%$ of potentially eligible patients were excluded. Such a large attrition rate reduces the generalizability of the study and may also introduce substantial selection bias (because patients lost to follow-up may be systematically different from those who remain). This paper extends our understanding of the behavioral characteristics associated with favorable and unfavorable surgical outcomes, and it applies the PROMIS battery in a novel and useful way, but more study is required in order to effectively change practice.

$$
\begin{array}{r}
\text { — Michael Glantz, MD } \\
\text { Hershey Medical Center } \\
\text { Hershey, Pennsylvania }
\end{array}
$$

$\mathrm{B}$ EFORE undergoing spine surgery, some patients report symptoms of depression and anxiety. ${ }^{1,9,13} \mathrm{Al}-$ though the reported correlations between preoperative depression/anxiety and specific postoperative surgical outcomes vary, overall, outcomes after spine surgery or other surgical procedures are worse in patients with psychological distress. $3,7,10,12$

We know less about how perioperative changes in depression and anxiety may affect postoperative outcomes. A simple correlation between preoperative psychological distress and postoperative outcomes may overlook the nuances of how a psychological disorder can change from before to after surgery, and how this may affect or be affected by the surgery itself. Importantly, psychological distress symptoms may improve in association with improvements in health after surgery. In a study of patients undergoing lumbar spine surgery, postoperative improvements in depression and anxiety were associated with improvements in pain, Oswestry Disability Index values, and fulfillment of patient expectations. ${ }^{9}$

Our objective was to analyze associations between changes in depression/anxiety from before and 12 months after spine surgery, as well as changes in Patient-Reported Outcomes Measurement Information System (PROMIS) scores at the same time points. We analyzed PROMIS scores in patients stratified according to perioperative changes in depression and anxiety symptoms, which were also measured using PROMIS. We hypothesized that patients whose depression/anxiety stayed the same or worsened after surgery, as well as those who developed depression/anxiety postoperatively, would have less improvement in PROMIS scores than those with no depression/anxiety at either time point. Additionally, we hypothesized that these 2 groups would have less improvement in PROMIS scores than those whose depression/anxiety improved postoperatively.

\section{Methods}

Institutional review board approval was obtained for this study.

\section{Patients and Data Collection}

Inclusion criteria for patient selection were as follows: English speaking; age > 18 years; surgery for lumbar or cervical spine degenerative disease or deformity at our institution from December 2014 through July 2019. At the preoperative and 12-month postoperative visits, patients 


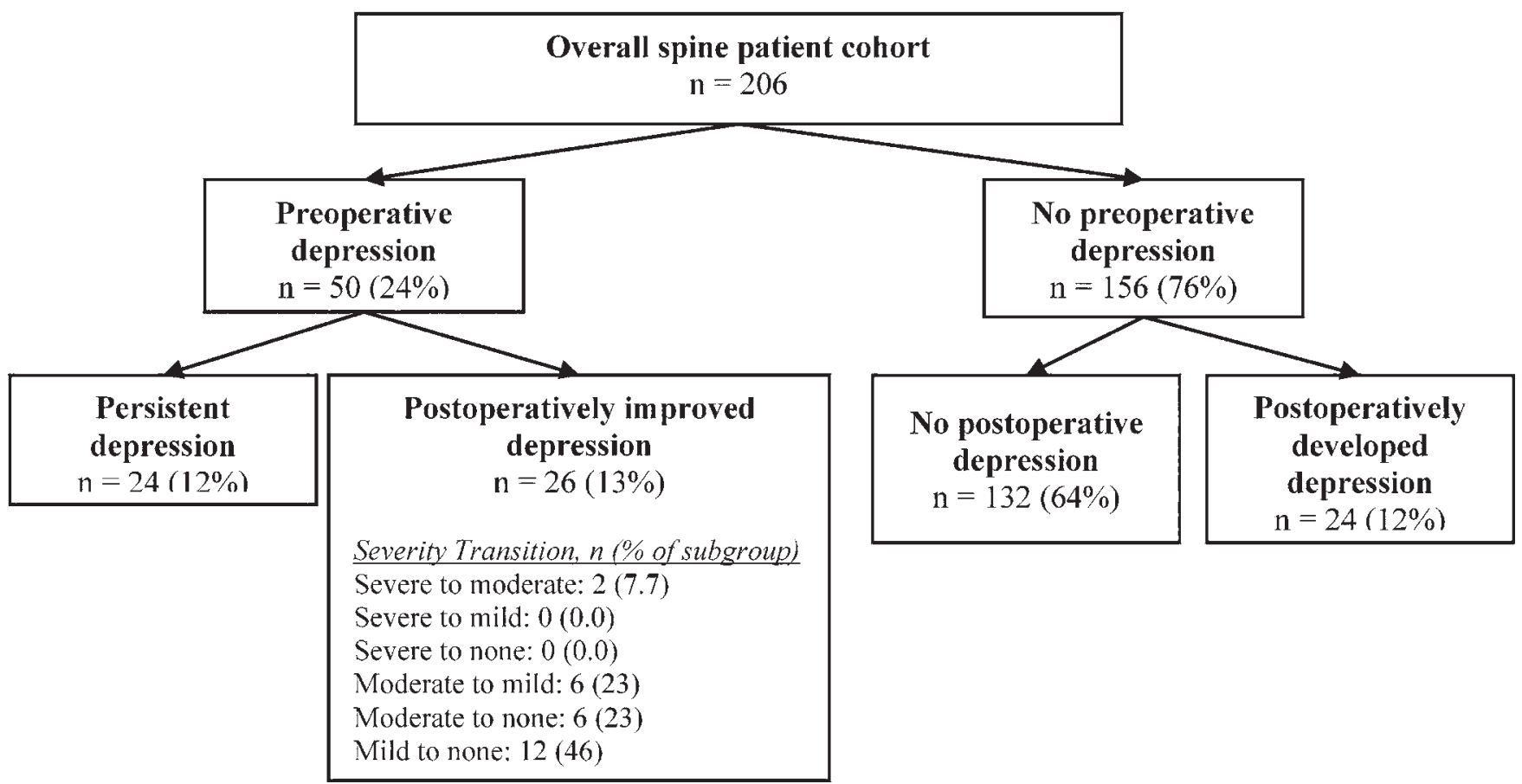

FIG. 1. Categorization of patients by changes in depression. The overall cohort consists of spine surgery patients with both preoperative and 12-month postoperative PROMIS scores for depression. Patients are categorized as those with 1) persistent depression (preoperatively positive for depression with same or worse depression postoperatively); 2) postoperatively improved depression (preoperatively positive for depression that was partially or completely resolved postoperatively); 3) no depression preoperatively or postoperatively; and 4) postoperatively developed depression.

were asked to complete surveys using PROMIS. Surveys assessed the PROMIS domains of depression, anxiety, pain interference, physical function, sleep disturbance, and satisfaction with participation in social roles (herein termed "social satisfaction"). Patients were excluded if they did not have complete data for these PROMIS domains at both the preoperative and 12-month postoperative time points. We also excluded patients who underwent more than a single spine surgery (in the setting of that surgery and on the same day [during one surgical encounter]), multiple procedures may have been performed to address the underlying pathology and were noted in the chart accordingly). The survey had a response rate of approximately $40 \%$. PROMIS domains are scored using a T-score-normalized method. For most domains, a score of 50 represents the mean of that domain for the US general population. The standard deviation for PROMIS domains is 10 points. For depression, anxiety, pain interference, and sleep disturbance domains, higher scores indicate more severe symptoms. For physical function and social satisfaction domains, lower scores indicate greater impairment. ${ }^{6}$ Previous work at our institution found the PROMIS domains of depression and anxiety to be reliable tools for identifying probable major depression and generalized anxiety in spine surgery patients..$^{13}$

Data were collected for demographic parameters, including patient age at the time of surgery, race, sex, marital status, current tobacco use, educational level, annual household income, and employment status. Data were also collected for surgery-associated factors, including preoperative diagnoses, procedures performed, surgery type, surgical approach, hospital length of stay (LOS), and preoperative pain dominance (back vs leg or neck vs arm). Patients scored their worst back pain, leg pain, neck pain, and/or arm pain on a scale ranging from 0 to 10 during the week before the preoperative visit. The dominance of back versus leg pain and neck versus arm pain was determined on the basis of these scores. Surgery type was for lumbar degenerative disease, lumbar deformity correction, cervical degenerative disease, or cervical deformity correction. Patients were included in the deformity categories if they were undergoing surgery for a diagnosis of scoliosis, including idiopathic or degenerative scoliosis. Otherwise, patients were included in the degenerative categories. No procedures or indications for surgery were excluded.

\section{Psychological Distress Severity}

PROMIS depression and PROMIS anxiety scores were classified in terms of disease severity according to the following criteria of the American Psychiatric Association?: $<55.0$ points, none; 55.0-59.9 points, mild; 60.0-69.9 points, moderate; or $\geq 70.0$ points, severe.

\section{Depression/Anxiety-Change Subgroups}

The overall cohort was analyzed separately for depression and anxiety. We term these separate cohorts the "depression cohort" (Fig. 1) and "anxiety cohort" (Fig. 2). For each analysis, patients were categorized into the following 4 change subgroups, representing preoperative to postoperative changes in depression/anxiety: 1) "persistent" for patients with mild, moderate, or severe preoperative de- 


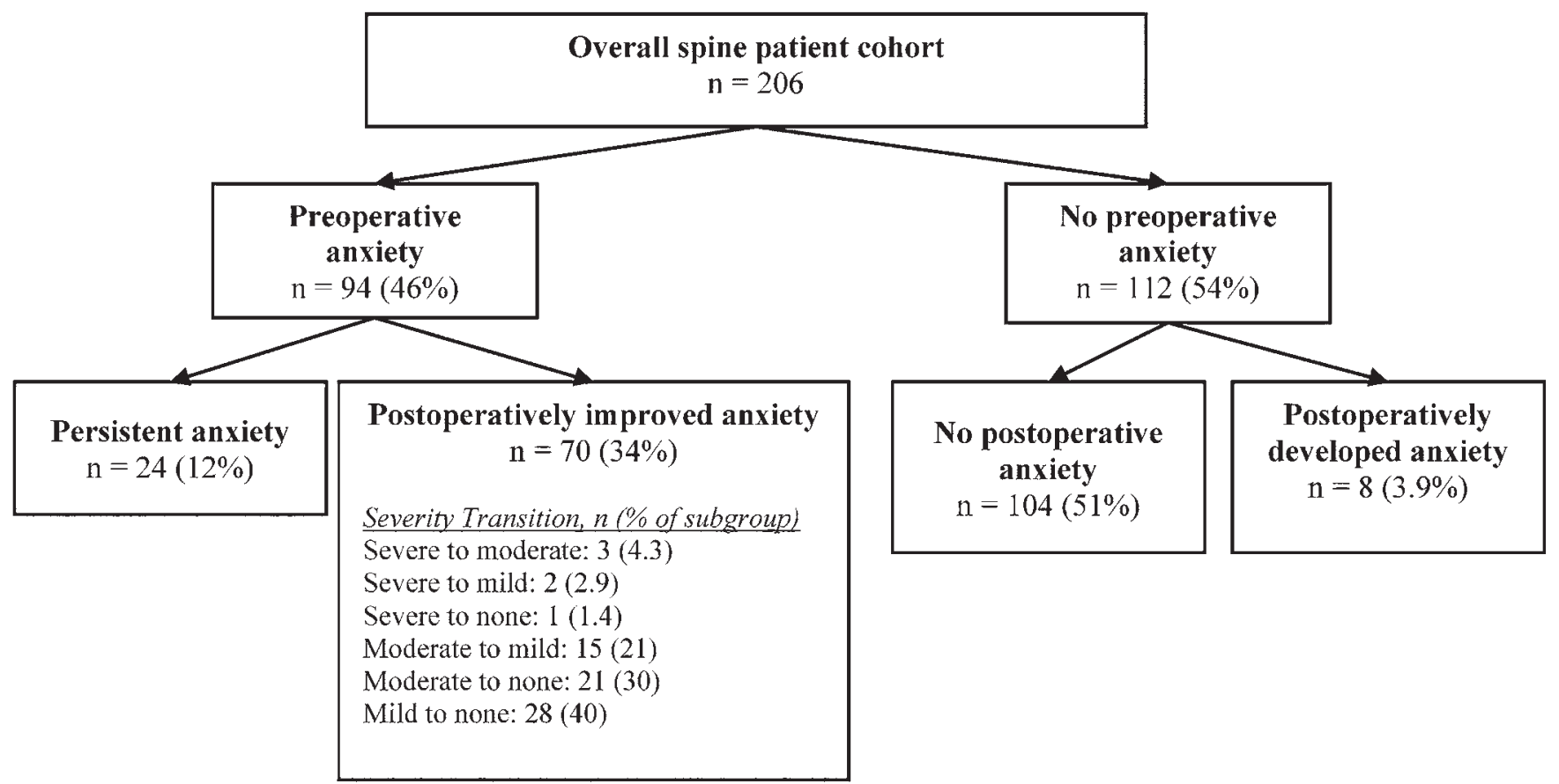

FIG. 2. Categorization of patients by changes in anxiety. The overall cohort consists of spine surgery patients with both preoperative and 12-month postoperative PROMIS scores for anxiety. Patients are categorized as those with 1) persistent anxiety (preoperatively positive for anxiety with same or worse anxiety postoperatively); 2) postoperatively improved anxiety (preoperatively positive for anxiety that was partially or completely resolved postoperatively); 3) no anxiety preoperatively or postoperatively; and 4) postoperatively developed anxiety.

pression/anxiety that stayed the same or worsened postoperatively; 2) "postoperatively improved" for patients with mild, moderate, or severe preoperative depression/anxiety that improved or resolved postoperatively; 3) "postoperatively developed" for patients with no preoperative depression/anxiety who developed depression/anxiety postoperatively; and 4) "no depression/anxiety" for patients who had no depression/anxiety at either time point.

\section{Outcome Variables: Change in PROMIS Scores}

Our 4 outcome variables of interest were perioperative change in PROMIS scores for pain interference, physical function, sleep disturbance, and social satisfaction. We calculated the change in these variables by subtracting the preoperative score from the 12-month postoperative score. A decrease in PROMIS pain interference (herein, "PROMIS pain") or PROMIS sleep disturbance score indicates an improvement, whereas an increase in PROMIS physical function or PROMIS satisfaction with participation in social roles (herein, "PROMIS-social satisfaction") score indicates an improvement.

\section{Statistical Analysis \\ Comparison of Characteristics Across Depression/Anxiety Subgroups}

Within each cohort, we assessed differences in the demographic parameters, surgery-associated factors, and PROMIS scores between the depression/anxiety subgroups. We used 1-way ANOVA tests for continuous variables and Fisher's exact tests for categorical variables to evaluate for significant differences between the subgroups. In cases in which Fisher's exact tests were necessary but exceeded computational limits, we used simulated $\mathrm{p}$ values.

\section{Associations Between Surgery Type and Change in PROMIS Score Outcomes}

We listed surgery-associated diagnoses and procedures across our cohort. Because many patients had multiple diagnoses and underwent multiple procedures performed on the same day and because the wide range of diagnoses and procedures would result in too many strata for analysis, we explored the broader category of surgery type as a potential confounder on the change in PROMIS scores. We also explored the relationship between surgery type and preoperative and changes in PROMIS scores using ANOVA in the overall cohort.

\section{Characteristics of Patients With Persistent Depression/Anxiety Versus Those With Postoperative Improvement}

We performed ANOVA and Fisher's tests to determine whether any preoperative characteristics (demographic parameters, surgery-associated factors, and preoperative PROMIS scores) differed significantly between the persistent depression/anxiety subgroup and the postoperatively improved depression/anxiety subgroup.

\section{Association Between Depression/Anxiety Subgroups and Change in PROMIS Scores}

To evaluate our primary hypothesis of the association 
between the depression/anxiety subgroups and change in PROMIS scores, we developed linear regression models. We performed univariate analysis of the effect of the depression/anxiety subgroups on each change in PROMIS score outcome to determine the unadjusted significance of the association.

We evaluated our data for potential confounding variables to include in our regression models, while avoiding overfitting of the model and unnecessary inclusion of nonconfounders. ${ }^{5,14}$ Confounders must be associated with the exposure of interest ${ }^{11}$ (i.e., depression/anxiety status change subgroups). We assessed this association using Fisher's exact tests and ANOVA tests, analyzing characteristics among the subgroups, as described above. The confounder must also be associated with the outcome of interest $^{11}$ (i.e., change in PROMIS score). Of those characteristics that were significantly different among the subgroups, we performed univariate regression of the characteristic on the change in PROMIS scores. These univariate regressions were performed in the no-depression and noanxiety groups to isolate the association between the potential confounder and the outcome from our exposure of interest. ${ }^{11}$ Characteristics with a significant association at this step were included as confounders in our multivariate regression model to test the confounder-adjusted association between depression/anxiety subgroup and change in PROMIS scores.

These univariate and multivariate models compared persistent, postoperatively improved, and postoperatively developed depression/anxiety groups to a baseline of no depression/anxiety. We also created models comparing the persistent and postoperatively developed depression/ anxiety groups with the postoperatively improved depression/anxiety groups.

\section{Significance Level}

All statistical tests used $\alpha=0.05$.

\section{Results}

\section{Preoperative Depression and Anxiety}

In the depression cohort, $24 \%$ of patients had some level of preoperative depression, and $52 \%$ of these individuals saw postoperative improvement in their depression (Fig. 1). In the anxiety cohort, $46 \%$ of patients had some level of preoperative anxiety, and $74 \%$ of these individuals saw postoperative improvement in their anxiety (Fig. 2). Of those who had postoperatively improved depression or anxiety, most had depression that transitioned from mild severity to no depression (46\% in depression, Fig. 1; $40 \%$ in anxiety, Fig. 2).

\section{Demographic Characteristics and Surgery-Associated Factors}

The demographic parameters that demonstrated significant differences across the depression/anxiety subgroups were educational level in the depression cohort $(\mathrm{p}<0.001)$ and annual household income in the depression cohort $(\mathrm{p}=0.01)$ (Table 1). The surgery-associated factors with significant differences across the subgroups were surgical approach in the anxiety cohort $(\mathrm{p}=0.03)$ and postoper- ative LOS in both the depression and anxiety cohorts ( $\mathrm{p}$ $<0.01$ and $\mathrm{p}=0.03$, respectively) (Table 1). Preoperative PROMIS scores in all domains also significantly varied across both the depression and anxiety subgroups ( $\mathrm{p}<$ 0.05 for all) (Table 1).

\section{Surgery Type}

Most patients in the overall cohort underwent lumbar degenerative surgery (56\%; Table 1). Preoperative surgery-associated diagnoses and procedures are listed for each surgery type (Supplementary Table). Surgery type was significantly associated with preoperative PROMIS pain $(\mathrm{p}<0.01)$, preoperative PROMIS physical function $(\mathrm{p}<0.01)$, preoperative PROMIS social satisfaction $(\mathrm{p}<$ $0.01)$, and change in PROMIS social satisfaction $(\mathrm{p}=0.04)$ scores (Table 2). However, because surgery type was not associated with depression or anxiety subgroups, it was not a possible confounder (Table 1).

\section{Characteristics of Patients With Persistent Depression or Anxiety Versus Those With Postoperative Improvement}

When comparing preoperative characteristics across patients with persistent depression/anxiety versus those with postoperatively improved depression/anxiety, the only significant difference was in annual household income $(\mathrm{p}<0.05$; Table 3$)$. The percentage of patients with annual income $>\$ 50,000$ was higher in the postoperatively improved group (69\%) than in the persistent depression group (33\%) (Table 1).

\section{Confounders in the Relationship Between Depression/ Anxiety Group and Changes in PROMIS Scores}

Because the comparison of depression/anxiety subgroups revealed significant differences in educational level, annual household income, surgical approach, LOS, and preoperative PROMIS score (Table 1), we performed a univariate analysis for each of these variables on the change in PROMIS score outcomes. Significant associations were found between surgical approach and change in PROMIS pain, physical function, sleep disturbance, and social satisfaction scores and between hospital LOS and change in PROMIS physical function score (Table 4). Each preoperative PROMIS score was significantly associated with the change in PROMIS score for that same domain (Table 4). These factors were thus determined to be confounders, which we controlled for in our multivariate models.

\section{Changes in Depression/Anxiety and Changes in PROMIS Scores}

After adjusting for confounders with multivariate linear regression, compared with patients with no depression, patients with persistent depression had significantly less improvement in PROMIS pain by 9.1 points $(95 \% \mathrm{CI}$ $4.3,14)$, physical function by 7.5 points $(95 \%$ CI $3.8,11)$, PROMIS sleep disturbance by 5.8 points $(95 \%$ CI $1.3,10)$, and social satisfaction by 9.6 points $(95 \%$ CI $4.7,15)$ (Table 5; Fig. 3). Compared with patients with postoperatively improved depression, patients with persistent depression had significantly less improvement in pain $(\beta=8.4[95 \%$ 


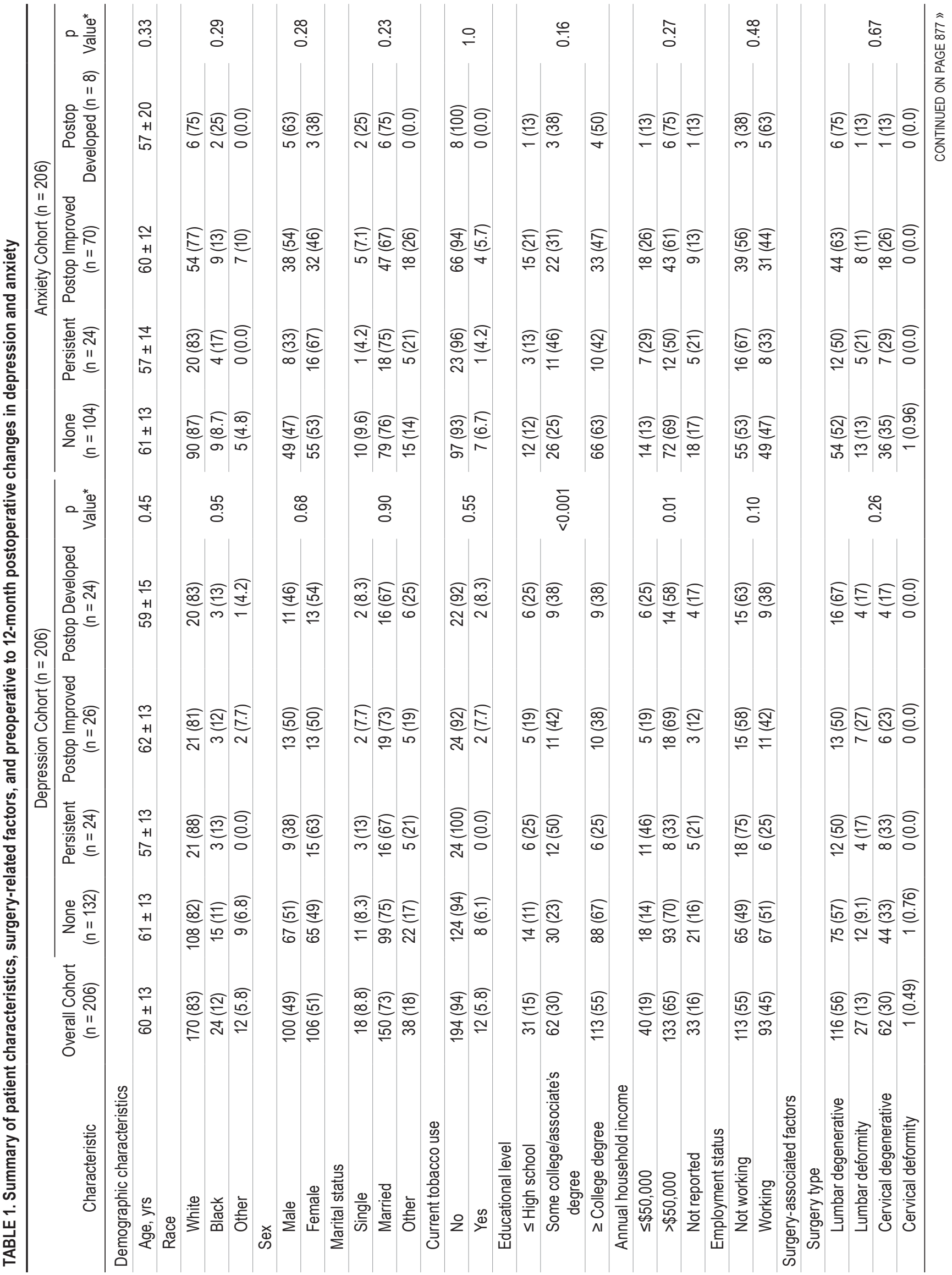




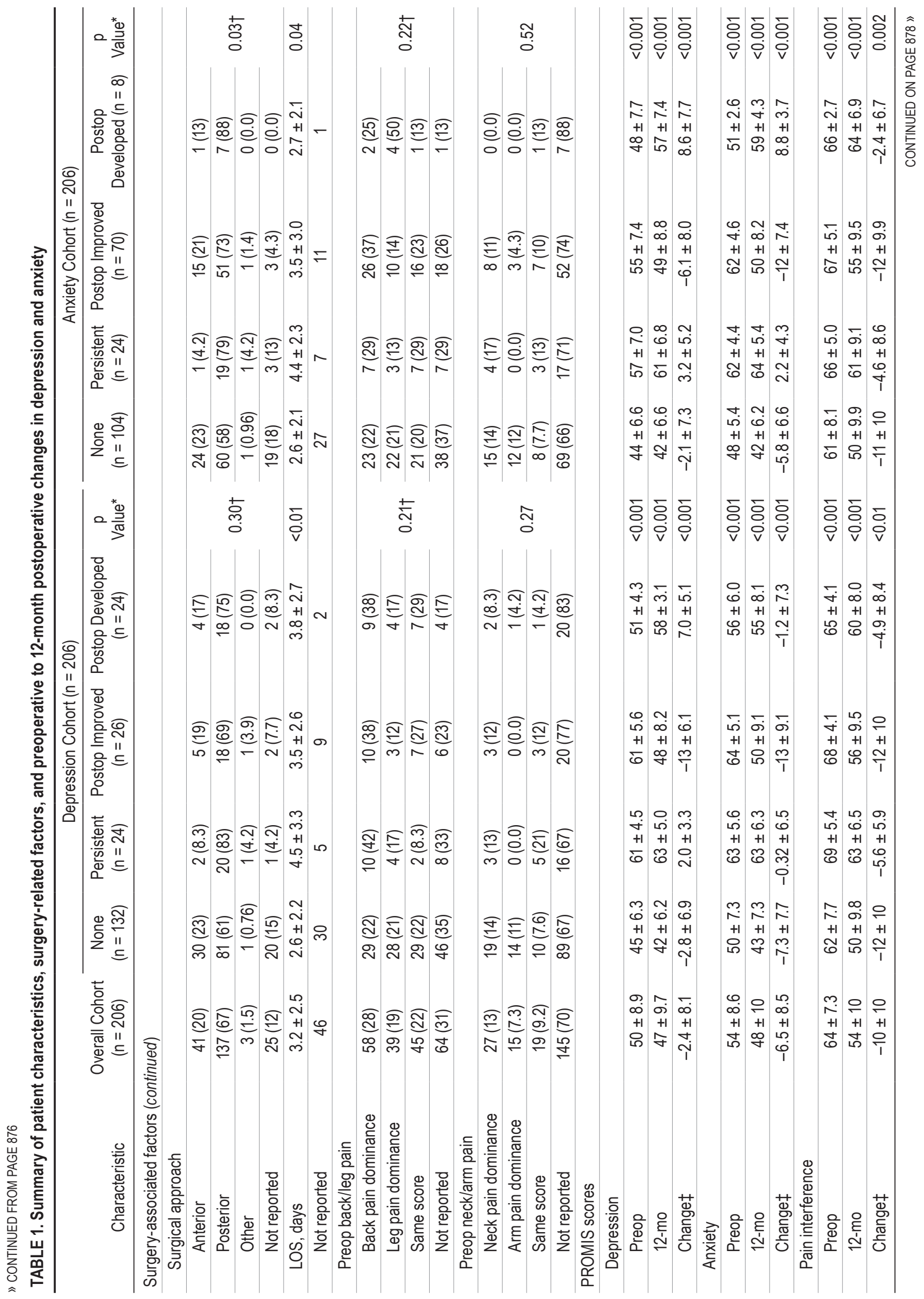




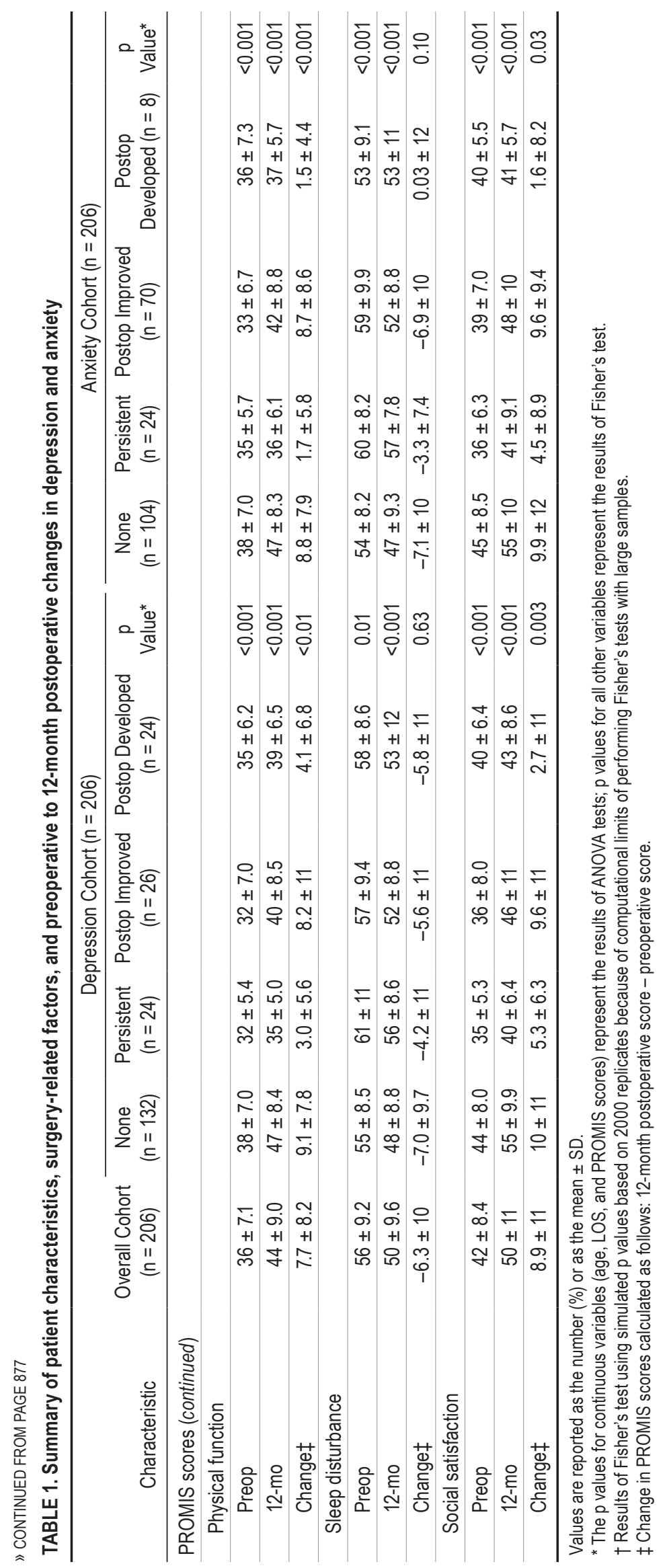


TABLE 2. Association between surgery type and change in preoperative scores and preoperative to postoperative PROMIS scores when comparing the type of surgery patients underwent

\begin{tabular}{cc}
\hline PROMIS Domain & $p$ Value \\
\hline Depression & \\
\hline Preoperative & 0.20 \\
\hline Change & 0.76 \\
\hline Anxiety & \\
\hline Preoperative & 0.18 \\
\hline Change & 0.43 \\
\hline Pain interference & \\
\hline Preoperative & $<0.01$ \\
\hline Change & 0.45 \\
\hline Physical function & 0.002 \\
\hline Preoperative & 0.70 \\
\hline Change & \\
\hline Sleep disturbance & 0.64 \\
\hline Preoperative & 0.96 \\
\hline Change & \\
\hline Social satisfaction & 0.001 \\
\hline Preoperative & 0.04 \\
\hline Change &
\end{tabular}

The $p$ values represent the results of ANOVA tests comparing differences in PROMIS domain values between surgery-type groups, as denoted in Table 1. The analysis was conducted in the overall patient cohort $(n=206)$.

CI 2.7, 14] ) and physical function ( $\beta=6.3[95 \%$ CI 1.6, 11]) scores (Table 6; Fig. 4).

Compared with patients with no depression, patients with postoperatively developed depression had significantly less improvement in PROMIS pain by 8.3 points $(95 \%$ CI $3.9,13)$, physical function by 5.4 points $(95 \%$ CI 2.0 , $8.9)$, and social satisfaction by 9.5 points $(95 \%$ CI $5.1,14)$ (Table 5; Fig. 3). Compared with patients with postoperatively improved depression, patients with postoperatively developed depression had significantly less improvement in pain scores $(\beta=6.9$ [95\% CI 1.1, 13]) (Table 6; Fig. 4).

In the anxiety cohort, after adjusting for confounders with multivariate analysis, compared with patients with no anxiety, patients with persistent anxiety had significantly less improvement in PROMIS physical function by 7.1 points $(95 \%$ CI 3.1, 11), sleep disturbance by 6.3 points $(95 \%$ CI $1.3,11)$, and social satisfaction by 8.1 points $(95 \%$ CI 2.4, 14) (Table 5; Fig. 5). Compared with patients with postoperatively improved anxiety, patients with persistent anxiety had significantly less improvement in pain $(\beta=$ 6.6 [95\% CI 0.90, 12]), physical function $(\beta=7.6$ [95\% CI $3.3,12])$, and social satisfaction $(\beta=7.0$ [95\% CI 1.5, 13]) scores (Table 6; Fig. 6).

Compared with patients with no anxiety, patients with postoperatively developed anxiety had significantly less improvement in PROMIS pain by 9.7 points (95\% CI 2.1, $17)$, physical function by 7.4 points $(95 \%$ CI $1.7,13)$, and social satisfaction by 9.7 points $(95 \%$ CI $2.0,17)$ (Table 5; Fig. 5). Compared with patients with postoperatively improved anxiety, patients with postoperatively developed
TABLE 3. Differences in preoperative characteristics between patients with persistent versus postoperatively improved depression/anxiety

\begin{tabular}{|c|c|c|}
\hline \multirow[b]{2}{*}{ Characteristic* } & \multicolumn{2}{|c|}{$p$ Value } \\
\hline & $\begin{array}{c}\text { Persistent }(n=24) \\
\text { vs Postoperatively } \\
\text { Improved }(n=26) \\
\text { Depressiont }\end{array}$ & $\begin{array}{c}\text { Persistent }(n=24) \\
\text { vs Postoperatively } \\
\text { Improved } \\
(n=70) \text { Anxiety } \dagger\end{array}$ \\
\hline \multicolumn{3}{|l|}{ Demographic parameters } \\
\hline Age & 0.19 & 0.33 \\
\hline Race & 0.59 & 0.32 \\
\hline Sex & 0.41 & 0.10 \\
\hline Marital status & 0.91 & 0.92 \\
\hline Current tobacco use & 0.49 & 1.0 \\
\hline Educational level & 0.62 & 0.43 \\
\hline Annual household income & $<0.05 \ddagger$ & 0.48 \\
\hline Employment status & 0.24 & 0.47 \\
\hline \multicolumn{3}{|l|}{ Surgery-associated factors } \\
\hline Surgery type & 0.66 & 0.39 \\
\hline Surgical approach & 0.74 & 0.07 \\
\hline LOS & 0.29 & 0.20 \\
\hline $\begin{array}{l}\text { Preop back vs leg pain } \\
\text { dominance }\end{array}$ & 0.40 & 0.86 \\
\hline $\begin{array}{l}\text { Preop neck vs arm pain } \\
\text { dominance }\end{array}$ & 0.74 & 0.74 \\
\hline \multicolumn{3}{|l|}{ Preop PROMIS scores } \\
\hline Depression & 0.66 & 0.15 \\
\hline Anxiety & 0.80 & 0.83 \\
\hline Pain interference & 0.56 & 0.42 \\
\hline Physical function & 0.94 & 0.39 \\
\hline Sleep disturbance & 0.31 & 0.39 \\
\hline Social satisfaction & 0.54 & 0.09 \\
\hline
\end{tabular}

*Values for each characteristic as presented in Table 1.

† The $p$ values for continuous variables (age, postoperative LOS, and PROMIS scores) represent the results of independent group t-tests comparing differences in the values between preoperative to postoperative depression/anxietychange subgroups. The $p$ values for all other variables represent the results of Fisher's test comparing differences in proportions across levels for each variable between preoperative to postoperative depression/anxiety-change subgroups.

† Fisher's tests compared income characteristic on all 3 levels: $\leq \$ 50,000$, $>\$ 50,000$, and not reported. A Fisher's test was also conducted using only the 2 levels of reported data $(\leq \$ 50,000$ and $>\$ 50,000)$ to further explore the significance of this characteristic. Significance remained at $\alpha=0.05$, with $p=$ 0.026 .

anxiety had significantly less improvement in pain $(\beta=$ $11[95 \%$ CI $2.7,19])$, physical function $(\beta=7.5[95 \% \mathrm{CI}$ $1.5,14])$, and social satisfaction $(\beta=8.1[95 \%$ CI $0.4,16])$ scores (Table 6; Fig. 6). The uncorrected univariate coefficients can be found in Tables 5 and 6 .

\section{Discussion}

We studied the association between perioperative changes in depression/anxiety and changes in pain interference, physical function, sleep disturbance, and satisfaction 
TABLE 4. Univariate linear regression model to test effect of potential confounders on change in PROMIS scores

\begin{tabular}{|c|c|c|c|c|}
\hline \multirow[b]{2}{*}{ Variable by Outcome } & \multicolumn{2}{|c|}{ No Depression $(n=132)$} & \multicolumn{2}{|c|}{ No Anxiety $(n=104)$} \\
\hline & $\beta(95 \% \mathrm{Cl})$ & p Value & $\beta(95 \% \mathrm{Cl})$ & p Value \\
\hline \multicolumn{5}{|l|}{ Change in pain interference } \\
\hline \multicolumn{5}{|l|}{ Educational level } \\
\hline Intercept* & $-13(-19,-18)$ & & $-9.4(-15,-3.6)$ & \\
\hline Some college/associate's degree & $1.2(-5.6,7.9)$ & 0.74 & $-2.8(-9.9,4.2)$ & 0.43 \\
\hline$\geq$ College degree & $2.1(-3.9,8.1)$ & 0.49 & $-1.1(-7.5,5.3)$ & 0.73 \\
\hline \multicolumn{5}{|l|}{ Income level } \\
\hline Intercept* & $-9.4(-14,-4.5)$ & & $-8.4(-14,-3.0)$ & \\
\hline$>\$ 50,000$ & $-2.6(-8.0,2.7)$ & 0.33 & $-2.8(-8.7,3.2)$ & 0.36 \\
\hline Not reported & $-2.7(-9.4,4.0)$ & 0.42 & $-3.2(-10,4.0)$ & 0.38 \\
\hline \multicolumn{5}{|l|}{ Surgical approach } \\
\hline Intercept* & $-13(-17,-9.6)$ & & $-13(-17,-9.8)$ & \\
\hline Posterior & $1.5(-2.6,5.7)$ & 0.46 & $3.6(-0.70,7.9)$ & 0.10 \\
\hline Other & $26(6.3,45)$ & 0.01 & $26(8.0,45)$ & 0.01 \\
\hline LOS† & $0.54(-0.42,1.5)$ & 0.27 & $0.99(-0.11,2.1)$ & 0.08 \\
\hline Preop pain interference & $-0.62(-0.83,-0.41)$ & $<0.001$ & $-0.55(-0.77,-0.32)$ & $<0.001$ \\
\hline Preop depression† & \multicolumn{2}{|c|}{$0.06(-0.10,0.21)$} & \multicolumn{2}{|c|}{0.46} \\
\hline Preop anxiety† & \multicolumn{2}{|c|}{$0.06(-0.11,0.22)$} & \multicolumn{2}{|c|}{0.49} \\
\hline \multicolumn{5}{|l|}{ Change in physical function } \\
\hline \multicolumn{5}{|l|}{ Educational level } \\
\hline Intercept* & $10(6.1,14)$ & & $7.9(3.4,12)$ & \\
\hline Some college/associate's degree & $-3.0(-8.0,2.0)$ & 0.24 & $-0.38(-5.9,5.1)$ & 0.89 \\
\hline$\geq$ College degree & $-0.64(-5.1,3.8)$ & 0.78 & $1.5(-3.4,6.5)$ & 0.54 \\
\hline \multicolumn{5}{|l|}{ Income level } \\
\hline Intercept* & $8.1(4.5,12)$ & & $7.3(3.1,11)$ & \\
\hline$>\$ 50,000$ & $0.90(-3.1,4.9)$ & 0.66 & $1.5(-3.1,6.1)$ & 0.52 \\
\hline Not reported & $1.9(-3.1,6.8)$ & 0.45 & $2.8(-2.8,8.4)$ & 0.32 \\
\hline \multicolumn{5}{|l|}{ Surgical approach } \\
\hline Intercept* & $9.3(6.7,12)$ & & $9.4(6.4,12)$ & \\
\hline Posterior & $-0.03(-3.1,3.1)$ & 0.98 & $-0.64(-4.2,2.9)$ & 0.72 \\
\hline Other & $-19(-34,4.4)$ & 0.01 & $-19(-34,-4.2)$ & 0.01 \\
\hline LOS† & $-0.80(-1.5,-0.14)$ & 0.02 & $-0.82(-1.6,-0.00)$ & $<0.05$ \\
\hline Preop physical function & $-0.39(-0.57,-0.21)$ & $<0.001$ & $-0.43(-0.63,-0.22)$ & $<0.001$ \\
\hline Preop depression $\ddagger$ & \multicolumn{2}{|c|}{$-0.08(-0.21,0.04)$} & \multicolumn{2}{|c|}{0.20} \\
\hline Preop anxiety $\ddagger$ & \multicolumn{2}{|c|}{$-0.10(-0.23,0.03)$} & \multicolumn{2}{|c|}{0.13} \\
\hline \multicolumn{5}{|l|}{ Change in sleep disturbance } \\
\hline \multicolumn{5}{|l|}{ Educational level } \\
\hline Intercept $^{\star}$ & $-8.1(-13,-3.0)$ & & $-6.2(-12,-0.17)$ & \\
\hline Some college/associate's degree & $2.6(-3.7,8.8)$ & 0.42 & $-0.40(-7.7,6.9)$ & 0.91 \\
\hline$\geq$ College degree & $0.94(-4.6,6.5)$ & 0.74 & $-1.3(-7.8,5.3)$ & 0.70 \\
\hline \multicolumn{5}{|l|}{ Income level } \\
\hline Intercept* & $-7.9(-12,-3.4)$ & & $-9.7(-15,-4.1)$ & \\
\hline$>\$ 50,000$ & $0.97(-4.0,5.9)$ & 0.70 & $2.8(-3.3,8.8)$ & 0.37 \\
\hline Not reported & $1.9(-4.3,8.1)$ & 0.55 & $3.8(-3.6,11)$ & 0.31 \\
\hline Surgical approach & & & & \\
\hline Intercept* & $-11(-15,-7.5)$ & & $-12(-16,-7.4)$ & \\
\hline Posterior & $4.8(0.63,9.0)$ & 0.025 & $5.3(0.13,10)$ & $<0.05$ \\
\hline Other & $11(-9.1,31)$ & 0.28 & $12(-10,33)$ & 0.30 \\
\hline
\end{tabular}


TABLE 4. Univariate linear regression model to test effect of potential confounders on change in PROMIS scores

\begin{tabular}{|c|c|c|c|c|}
\hline \multirow[b]{2}{*}{ Variable by Outcome } & \multicolumn{2}{|c|}{ No Depression $(n=132)$} & \multicolumn{2}{|c|}{ No Anxiety $(n=104)$} \\
\hline & $\beta(95 \% \mathrm{Cl})$ & $p$ Value & $\beta(95 \% \mathrm{Cl})$ & p Value \\
\hline \multicolumn{5}{|l|}{ Change in sleep disturbance (continued) } \\
\hline LOS† & $0.55(-0.37,1.5)$ & 0.24 & $0.84(-0.37,2.0)$ & 0.17 \\
\hline Preop sleep disturbance & $-0.61(-0.78,-0.44)$ & $<0.001$ & $-0.66(-0.88,-0.45)$ & $<0.001$ \\
\hline Preop depression $\ddagger$ & \multicolumn{2}{|c|}{$-0.02(-0.18,0.13)$} & \multicolumn{2}{|c|}{0.76} \\
\hline Preop anxiety & \multicolumn{2}{|c|}{$0.09(-0.08,0.25)$} & \multicolumn{2}{|c|}{0.30} \\
\hline \multicolumn{5}{|l|}{ Change in social satisfaction } \\
\hline \multicolumn{5}{|l|}{ Educational level } \\
\hline Intercept* & $14(8.4,20)$ & & $11(3.9,17)$ & \\
\hline Some college/associate's degree & $-4.3(-11,2.7)$ & 0.22 & $-0.03(-8.2,8.1)$ & 0.99 \\
\hline$\geq$ College degree & $-4.1(-10,2.1)$ & 0.19 & $-1.2(-8.6,6.1)$ & 0.75 \\
\hline \multicolumn{5}{|l|}{ Income level } \\
\hline Intercept* $^{*}$ & $10(5.0,15)$ & & $10(4.2,17)$ & \\
\hline$>\$ 50,000$ & $0.22(-5.4,5.8)$ & 0.94 & $-0.78(-7.6,6.1)$ & 0.82 \\
\hline Not reported & $1.4(-5.6,8.3)$ & 0.70 & $0.31(-9.0,8.7)$ & 0.94 \\
\hline \multicolumn{5}{|l|}{ Surgical approach } \\
\hline Intercept* & $12(7.9,15)$ & & $11(6.8,16)$ & \\
\hline Posterior & $-1.5(-5.8,2.8)$ & 0.48 & $-2.2(-7.5,3.1)$ & 0.41 \\
\hline Other & $-40(-60,-19)$ & $<0.001$ & $-40(-62,-17)$ & $<0.001$ \\
\hline LOS† & $-0.86(-1.8,0.11)$ & 0.08 & $-0.94(-2.2,0.32)$ & 0.14 \\
\hline Preop social satisfaction & $-0.66(-0.87,-0.46)$ & $<0.001$ & $-0.75(-0.98,-0.52)$ & $<0.001$ \\
\hline Preop depression $\ddagger$ & \multicolumn{2}{|c|}{$-0.04(-0.21,0.13)$} & \multicolumn{2}{|c|}{0.63} \\
\hline Preop anxiety $\ddagger$ & \multicolumn{2}{|c|}{$-0.08(-0.25,0.09)$} & \multicolumn{2}{|c|}{0.36} \\
\hline
\end{tabular}

* For categorical variables in linear regression models, one level of the variable is selected as a base level to determine the intercept coefficient. The remaining regression coefficients are then calculated for the remaining levels of the variable. Thus, for the categorical variables presented here, the first level of the variable, as presented in Table 1, is not listed in this table and is instead used as the base variable to calculate the intercept coefficient. The variable is considered significantly associated with the outcome if the regression coefficients for the remaining levels demonstrate significant $p$ values.

$\dagger$ For continuous variables in linear regression models, the coefficient represents the effect that a 1-point increase in this tested variable would have on the outcome variable. The variable is considered significantly associated with the outcome if the regression coefficients for the remaining levels demonstrate significant $p$ values. $\ddagger$ The effect of preoperative depression and preoperative anxiety scores was tested in the entire cohort $(n=206)$ and not in the no-depression or no-anxiety subgroups, because these subgroups would not provide a representative sample of the range of depression and anxiety scores in the entire cohort.

with participation in social roles in spine surgery patients. Almost all groups of patients with different depression/ anxiety perioperative change patterns experienced improvement in each of the 4 domains postoperatively, with the exception of patients who, postoperatively, had developed anxiety, who experienced worse sleep disturbance. However, these groups differed significantly in the degree of improvement. We found that spine surgery patients with any postoperative depression, either persistent (having been present preoperatively) or new onset (developed postoperatively), had significantly less improvement in several PROMIS domain scores from preoperatively to 12 months postoperatively compared with patients who had no depression at either time point, as well as compared with patients who had preoperative depression that improved postoperatively. Similarly, patients who had persistent or postoperatively developed anxiety had significantly less improvement in PROMIS domain scores compared with patients who had no anxiety at either time point, as well as compared with patients whose anxiety improved postop- eratively. Thus, the postoperative presence of persistent or new-onset psychological distress may have more bearing on improvement in PROs than the preoperative presence of psychological distress. This suggests that treatment of preoperative depression/anxiety, or screening and treatment of new postoperative depression/anxiety, may result in better postoperative PROs.

This idea is novel compared with most recent research done regarding surgical spine patients, which focuses on the association between preoperative psychological distress and postoperative patient health. For example, studies of elderly patients undergoing revision lumbar surgery showed that increased preoperative depression was associated with patient dissatisfaction 2 years after surgery. ${ }^{1}$ One study ${ }^{4}$ that did consider postoperative depression in spine surgery patients found that these patients had worse functional outcomes, and those who became depressed after surgery had greater dissatisfaction. Our results are consistent with these findings. Our analysis differs in that the previous study was conducted in patients with lumbar 
TABLE 5. Linear regression models of changes in preoperative to postoperative PROMIS scores when comparing depression/anxiety change subgroups relative to persistent depression/anxiety

\begin{tabular}{|c|c|c|c|c|c|}
\hline \multirow[b]{2}{*}{ Outcome } & \multicolumn{2}{|c|}{ Unadjusted } & \multicolumn{3}{|c|}{ Adjusted $†$} \\
\hline & $\beta(95 \% \mathrm{Cl})^{*}$ & p Value & Covariates & $\beta(95 \% \mathrm{Cl})^{*}$ & p Value \\
\hline \multicolumn{6}{|l|}{ Depression cohort $(n=206)$} \\
\hline \multicolumn{6}{|c|}{ Change in pain interference } \\
\hline Intercept & $-12(-13,-10)$ & & & $21(6.6,36)$ & \\
\hline Persistent & $6.1(1.8,10)$ & 0.01 & & $9.1(4.3,14)$ & $<0.001$ \\
\hline Postop improved & $-0.28(-4.4,3.9)$ & 0.90 & & $1.1(-3.8,6.1)$ & 0.66 \\
\hline \multirow[t]{6}{*}{ Postop developed } & $6.8(2.5,11)$ & $<0.01$ & & $8.3(3.9,13)$ & $<0.001$ \\
\hline & & & Surgical approach & & \\
\hline & & & Posterior & $3.3(-0.26,7.0)$ & 0.07 \\
\hline & & & Other & $4.9(-6.1,16)$ & 0.38 \\
\hline & & & LOS & $-0.11(-0.74,0.52)$ & 0.73 \\
\hline & & & Preop pain interference & $-0.57(-0.80,-0.33)$ & $<0.001$ \\
\hline \multicolumn{6}{|c|}{ Change in physical function } \\
\hline Intercept & $9.1(7.7,10)$ & & & $31(23,38)$ & \\
\hline Persistent & $-6.1(-9.5,-2.6)$ & $<0.001$ & & $-7.5(-11,-3.8)$ & $<0.001$ \\
\hline Postop improved & $-0.84(-4.2,2.5)$ & 0.62 & & $-1.6(-5.3,2.2)$ & 0.42 \\
\hline \multirow[t]{6}{*}{ Postop developed } & $-5.0(-8.5,-1.5)$ & $<0.01$ & & $-5.4(-8.9,-2.0)$ & $<0.01$ \\
\hline & & & Surgical approach & & \\
\hline & & & Posterior & $-2.3(-5.2,0.52)$ & 0.11 \\
\hline & & & Other & $-3.7(-12,4.8)$ & 0.39 \\
\hline & & & LOS & $-0.35(-0.84,0.14)$ & 0.16 \\
\hline & & & Preop physical function & $-0.51(-0.68,-0.33)$ & $<0.001$ \\
\hline \multicolumn{6}{|c|}{ Change in sleep disturbance } \\
\hline Intercept & $-7.0(-8.7,-5.2)$ & & & $24(15,34)$ & \\
\hline Persistent & $2.8(-1.7,7.2)$ & 0.22 & & $5.8(1.3,10)$ & 0.01 \\
\hline Postop improved & $1.3(-3.0,5.6)$ & 0.54 & & $4.1(-0.55,8.7)$ & 0.08 \\
\hline \multirow[t]{6}{*}{ Postop developed } & $1.1(-3.3,5.6)$ & 0.62 & & $2.3(-2.0,6.6)$ & 0.29 \\
\hline & & & Surgical approach & & \\
\hline & & & Posterior & $2.2(-1.4,5.7)$ & 0.22 \\
\hline & & & Other & $1.2(-9.7,12)$ & 0.83 \\
\hline & & & LOS & $0.05(-0.56,0.66)$ & 0.88 \\
\hline & & & Preop sleep disturbance & $-0.61(-0.77,-0.45)$ & $<0.001$ \\
\hline \multicolumn{6}{|c|}{ Change in social satisfaction } \\
\hline Intercept & $10(8.7,12)$ & & & $44(34,54)$ & \\
\hline Persistent & $-5.2(-9.8,-0.64)$ & 0.03 & & $-9.6(-15,-4.7)$ & $<0.001$ \\
\hline Postop improved & $-0.84(-5.3,3.6)$ & 0.71 & & $-4.9(-9.8,0.06)$ & 0.05 \\
\hline \multirow[t]{6}{*}{ Postop developed } & $-7.7(-12,-3.2)$ & 0.001 & & $-9.5(-14,-5.1)$ & $<0.001$ \\
\hline & & & Surgical approach & & \\
\hline & & & Posterior & $-3.2(-6.9,0.50)$ & 0.09 \\
\hline & & & Other & $-5.0(-16,6.2)$ & 0.38 \\
\hline & & & LOS & $-0.35(-1.0,0.29)$ & 0.28 \\
\hline & & & Preop social satisfaction & $-0.68(-0.89,-0.47)$ & $<0.001$ \\
\hline \multicolumn{6}{|l|}{ Anxiety cohort $(n=206)$} \\
\hline \multicolumn{6}{|c|}{ Change in pain interference } \\
\hline Intercept & $-11(-13,-9.0)$ & & & $17(1.5,32)$ & \\
\hline Persistent & $6.2(1.9,11)$ & $<0.01$ & & $5.3(-0.12,11)$ & 0.06 \\
\hline Postop improved & $-1.2(-4.2,1.8)$ & 0.43 & & $-0.43(-4.0,3.1)$ & 0.81 \\
\hline
\end{tabular}


» CONTINUED FROM PAGE 882

TABLE 5. Linear regression models of changes in preoperative to postoperative PROMIS scores when comparing depression/anxiety change subgroups relative to persistent depression/anxiety

\begin{tabular}{|c|c|c|c|c|c|}
\hline \multirow[b]{2}{*}{ Outcome } & \multicolumn{2}{|c|}{ Unadjusted } & \multicolumn{3}{|c|}{ Adjusted $†$} \\
\hline & $\beta(95 \% \mathrm{Cl})^{*}$ & p Value & Covariates & $\beta(95 \% \mathrm{Cl})^{*}$ & p Value \\
\hline \multicolumn{6}{|c|}{ Anxiety cohort $(n=206)$ (continued) } \\
\hline \multicolumn{6}{|c|}{ Change in pain interference (continued) } \\
\hline \multirow[t]{6}{*}{ Postop developed } & $8.5(1.4,16)$ & 0.02 & & $9.7(2.1,17)$ & 0.01 \\
\hline & \multicolumn{5}{|c|}{ Surgical approach } \\
\hline & & & Posterior & $2.9(-0.90,6.7)$ & 0.13 \\
\hline & & & Other & $4.8(-6.5,16)$ & 0.41 \\
\hline & & & LOS & $0.20(-0.45,0.85)$ & 0.55 \\
\hline & & & Preop pain interference & $-0.48(-0.73,-0.23)$ & $<0.001$ \\
\hline \multicolumn{6}{|c|}{ Change in physical function } \\
\hline Intercept & $8.8(7.3,10)$ & & & $28(20,35)$ & \\
\hline Persistent & $-7.0(-11,-3.5)$ & $<0.001$ & & $-7.1(-11,-3.1)$ & $<0.001$ \\
\hline Postop improved & $-0.06(-11,-3.5)$ & 0.96 & & $-0.03(-2.6,2.5)$ & 0.98 \\
\hline \multirow[t]{6}{*}{ Postop developed } & $-7.2(-13,-1.6)$ & 0.01 & & $-7.4(-13,-1.7)$ & 0.01 \\
\hline & & & Surgical approach & & \\
\hline & & & Posterior & $-1.7(-4.6,1.2)$ & 0.26 \\
\hline & & & Other & $-3.0(-11,5.5)$ & 0.49 \\
\hline & & & LOS & $-0.53(-1.0,-0.04)$ & 0.04 \\
\hline & & & Preop physical function & $-0.44(-0.62,-0.27)$ & $<0.001$ \\
\hline \multicolumn{6}{|c|}{ Change in sleep disturbance } \\
\hline Intercept & $-7.1(-9.1,-5.2)$ & & & $25(15,35)$ & \\
\hline Persistent & $3.8(-0.66,8.3)$ & 0.09 & & $6.3(1.3,11)$ & 0.02 \\
\hline Postop improved & $0.17(-2.9,3.2)$ & 0.91 & & $2.9(-0.20,6.0)$ & 0.07 \\
\hline \multirow[t]{6}{*}{ Postop developed } & $7.1(-0.12,14)$ & 0.05 & & $5.9(-1.1,13)$ & 0.10 \\
\hline & & & Surgical approach & & \\
\hline & & & Posterior & $1.7(-1.9,5.3)$ & 0.36 \\
\hline & & & Other & $1.3(-9.6,12)$ & 0.81 \\
\hline & & & LOS & $0.12(-0.49,0.72)$ & 0.71 \\
\hline & & & Preop sleep disturbance & $-0.62(-0.79,-0.46)$ & $<0.001$ \\
\hline \multicolumn{6}{|c|}{ Change in social satisfaction } \\
\hline Intercept & $9.9(7.9,12)$ & & & $41(31,52)$ & \\
\hline Persistent & $-5.4(-10,-0.70)$ & 0.03 & & $-8.1(-14,-2.4)$ & 0.01 \\
\hline Postop improved & $-0.36(-3.6,2.9)$ & 0.83 & & $-1.8(-5.3,1.7)$ & 0.32 \\
\hline \multirow[t]{6}{*}{ Postop developed } & $-8.3(-16,-0.68)$ & 0.03 & & $-9.7(-17,-2.0)$ & 0.01 \\
\hline & & & Surgical approach & & \\
\hline & & & Posterior & $-2.7(-6.6,1.2)$ & 0.18 \\
\hline & & & Other & $-5.2(-17,6.5)$ & 0.38 \\
\hline & & & LOS & $-0.62(-1.3,0.06)$ & 0.07 \\
\hline & & & Preop social satisfaction & $-0.64(-0.86,-0.42)$ & $<0.001$ \\
\hline
\end{tabular}

\footnotetext{
${ }^{*}$ For categorical variables in linear regression models, one level of the variable is selected as a base level to determine the intercept coefficient. The remaining regression coefficients are then calculated for the remaining levels of the variable. Thus, for the categorical variables presented here, the first level of the variable, as presented in Table 1, is not listed in this table and is instead used as the base variable to calculate the intercept coefficient. The variable is considered significantly associated with the outcome if the regression coefficients for the remaining levels demonstrate significant $p$ values. For continuous variables in linear regression models, the coefficient represents the effect that a 1-point increase in the covariate would have on the outcome variable. The variable is considered significantly associated with the outcome if the regression coefficients for the remaining levels demonstrate significant $p$ values.

$\dagger$ The covariates selected in addition to the depression/anxiety status change subgroups are variables that were determined to be possible confounders because of significant differences between the subgroups (determined by ANOVA or Fisher's testing in Table 1) and were significantly associated with the outcome variables-the changes in PROMIS scores (determined by univariate regression on the outcomes in Table 5).
} 


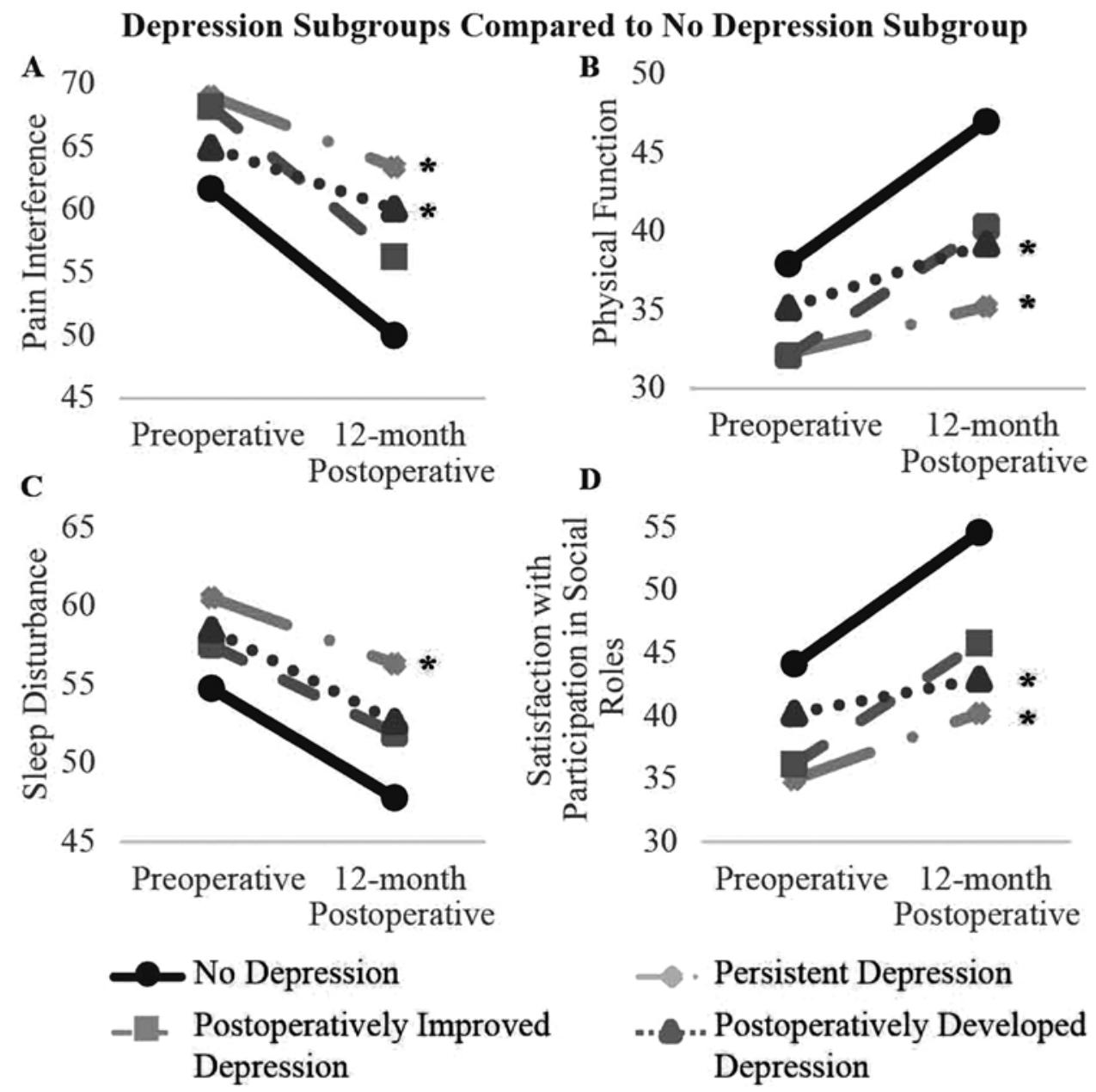

FIG. 3. Comparison of changes in preoperative and 12-month postoperative PROMIS scores between depression-change subgroups, compared with the no-depression subgroup. Preoperative and 12-month postoperative line markers indicate the observed mean PROMIS scores for each depression subgroup. All groups of patients with different depression perioperative change patterns experienced improvement in each of the 4 outcomes postoperatively. However, these groups differed significantly in the degree of improvement. Asterisks indicate significant differences between each subgroup and the no-depression subgroup with regard to changes in PROMIS scores 12 months postoperatively compared with those preoperatively after adjusting for confounders (surgical approach, hospital LOS, and preoperative score for the PROMIS domain being measured) via multiple linear regression. A: For the PROMIS pain interference domain, the following patients had significantly less improvement compared with patients with no depression: patients with persistent depression by 9.1 points $(95 \% \mathrm{Cl} 4.3,14)$ and patients with postoperatively developed depression by 8.3 points $(95 \% \mathrm{Cl} 3.9,13)$. B: For the PROMIS physical function domain, patients with persistent depression had less improvement by 7.5 points $(95 \% \mathrm{Cl} 3.8,11)$ and those with postoperatively developed depression by 5.4 points $(95 \% \mathrm{Cl} 2.0$, 8.9). C: For the PROMIS sleep disturbance domain, patients with persistent depression had less improvement by 5.8 points $(95 \%$ $\mathrm{CI} 1.3,10)$. D: For the PROMIS social satisfaction domain, patients with persistent depression had less improvement by 9.6 points $(95 \% \mathrm{Cl} 4.7,15)$ and patients with postoperatively developed depression had less improvement by 9.5 points $(95 \% \mathrm{Cl} 5.1,14)$.

degenerative conditions and analyzed depression only, whereas we included patients with any surgically treated spine degenerative disease or deformity and analyzed both anxiety and depression. It is also important to note that in almost all depression/anxiety change groups, we found improvement in each of the 4 PROMIS domains studied.

Our analysis controlled for our identified confounders of surgical approach, hospital LOS, and the preoperative score for the PROMIS domain of interest. By examining each of these variables' effects on changes in PROMIS score in the no-depression/no-anxiety groups, we found that the anterior (as opposed to posterior) surgical approach was associated with greater improvement in sleep disturbance and that longer LOS was associated with less improvement in physical function. Worse preoperative PROMIS scores were associated with greater improvement in that domain; for example, a worse preoperative PROMIS pain interference score was associated with greater improvement in pain. Most of the significant associations between depression/anxiety change groups were strengthened by controlling for these confounders (Tables 5 and 6).

Our study suggests that depression and anxiety should be viewed as dynamic conditions that may change during the perioperative period. Indeed, $52 \%$ of patients with preoperative depression and $74 \%$ of patients with preoperative 
TABLE 6. Linear regression models of changes in preoperative to postoperative PROMIS scores when comparing depression/anxiety change subgroups relative to postoperatively improved depression/anxiety

\begin{tabular}{|c|c|c|c|c|c|}
\hline \multirow[b]{2}{*}{ Outcome } & \multicolumn{2}{|c|}{ Unadjusted } & \multicolumn{3}{|c|}{ Adjusted $†$} \\
\hline & $\beta(95 \% \mathrm{Cl})^{*}$ & p Value & Covariates & $\beta(95 \% \mathrm{Cl})^{*}$ & $p$ Value \\
\hline \multicolumn{6}{|l|}{ Depression cohort $(n=74)$} \\
\hline \multicolumn{6}{|c|}{ Change in pain interference } \\
\hline Intercept & $-12(-15,-8.6)$ & & & $21(-14,56)$ & \\
\hline Persistent & $6.3(1.5,11)$ & 0.01 & & $8.4(2.7,14)$ & 0.005 \\
\hline \multirow[t]{6}{*}{ Postop developed } & $7.1(2.3,12)$ & 0.005 & & $6.9(1.1,13)$ & 0.02 \\
\hline & & & Surgical approach & & \\
\hline & & & Posterior & $4.5(-2.0,11)$ & 0.17 \\
\hline & & & Other & $-3.6(-17,9.6)$ & 0.59 \\
\hline & & & LOS & $-0.72(-1.6,0.13)$ & 0.095 \\
\hline & & & Preop pain interference & $-0.52(-1.0,-0.002)$ & 0.049 \\
\hline \multicolumn{6}{|c|}{ Change in physical function } \\
\hline Intercept & $8.2(5.0,11)$ & & & $36(24,49)$ & \\
\hline Persistent & $-5.2(-9.9,-0.56)$ & 0.029 & & $-6.3(-11,-1.6)$ & 0.01 \\
\hline \multirow[t]{6}{*}{ Postop developed } & $-4.2(-8.8,0.49)$ & 0.079 & & $-3.2(-7.8,1.4)$ & 0.17 \\
\hline & & & Surgical approach & & \\
\hline & & & Posterior & $-4.9(-10,0.44)$ & 0.07 \\
\hline & & & Other & $-0.65(-12,10)$ & 0.91 \\
\hline & & & LOS & $0.25(-0.45,0.94)$ & 0.48 \\
\hline & & & Preop physical function & $-0.74(-1.1,-0.42)$ & $<0.001$ \\
\hline \multicolumn{6}{|c|}{ Change in sleep disturbance } \\
\hline Intercept & $-5.6(-9.9,-1.3)$ & & & $32(15,49)$ & \\
\hline Persistent & $1.4(-4.8,7.6)$ & 0.65 & & $2.6(-3.7,8.9)$ & 0.40 \\
\hline \multirow[t]{6}{*}{ Postop developed } & $-0.21(-6.4,6.0)$ & 0.95 & & $-1.4(-7.4,4.7)$ & 0.65 \\
\hline & & & Surgical approach & & \\
\hline & & & Posterior & $0.20(-6.8,7.3)$ & 0.95 \\
\hline & & & Other & $-1.4(-16,13)$ & 0.85 \\
\hline & & & LOS & $-0.53(-1.5,0.40)$ & 0.26 \\
\hline & & & Preop sleep disturbance & $-0.61(-0.88,-0.34)$ & $<0.001$ \\
\hline \multicolumn{6}{|c|}{ Change in social satisfaction } \\
\hline Intercept & $9.6(5.9,13)$ & & & $40(23,57)$ & \\
\hline Persistent & $-4.4(-9.8,1.0)$ & 0.11 & & $-5.5(-11,0.29)$ & 0.06 \\
\hline \multirow[t]{6}{*}{ Postop developed } & $-6.9(-12,-1.5)$ & 0.01 & & $-4.0(-9.6,1.7)$ & 0.16 \\
\hline & & & Surgical approach & & \\
\hline & & & Posterior & $-4.5(-11,2.1)$ & 0.18 \\
\hline & & & Other & $6.2(-7.2,20)$ & 0.36 \\
\hline & & & LOS & $0.37(-0.49,1.2)$ & 0.40 \\
\hline & & & Preop social satisfaction & $-0.77(-1.1,-0.40)$ & $<0.001$ \\
\hline \multicolumn{6}{|l|}{ Anxiety cohort $(n=102)$} \\
\hline \multicolumn{6}{|c|}{ Change in pain interference } \\
\hline Intercept & $-12(-14,-9.8)$ & & & $31(0.19,61)$ & \\
\hline Persistent & $7.4(3.0,23)$ & 0.001 & & $6.6(0.90,12)$ & 0.02 \\
\hline \multirow[t]{6}{*}{ Postop developed } & $9.7(2.7,17)$ & 0.007 & & $11(2.7,19)$ & 0.01 \\
\hline & & & Surgical approach & & \\
\hline & & & Posterior & $-0.21(-6.4,5.9)$ & 0.95 \\
\hline & & & Other & $-4.6(-20,10)$ & 0.54 \\
\hline & & & LOS & $0.09(-0.76,0.94)$ & 0.84 \\
\hline & & & Preop pain interference & $-0.65(-1.1,-0.19)$ & 0.0068 \\
\hline
\end{tabular}


» CONTINUED FROM PAGE 885

TABLE 6. Linear regression models of changes in preoperative to postoperative PROMIS scores when comparing depression/anxiety change subgroups relative to postoperatively improved depression/anxiety

\begin{tabular}{|c|c|c|c|c|c|}
\hline \multirow[b]{2}{*}{ Outcome } & \multicolumn{2}{|c|}{ Unadjusted } & \multicolumn{3}{|c|}{ Adjusted $\dagger$} \\
\hline & $\beta(95 \% \mathrm{Cl})^{*}$ & $p$ Value & Covariates & $\beta(95 \% \mathrm{Cl})^{*}$ & p Value \\
\hline \multicolumn{6}{|c|}{ Anxiety cohort $(n=102)$ (continued) } \\
\hline \multicolumn{6}{|c|}{ Change in physical function } \\
\hline Intercept & $8.7(6.9,11)$ & & & $27(15,38)$ & \\
\hline Persistent & $-7.0(-11,-3.3)$ & $<0.001$ & & $-7.6(-12,-3.3)$ & $<0.001$ \\
\hline \multirow[t]{6}{*}{ Postop developed } & $-7.2(-13,-1.4)$ & 0.015 & & $-7.5(-14,-1.5)$ & 0.015 \\
\hline & & & Surgical approach & & \\
\hline & & & Posterior & $-0.37(-5.0,4.3)$ & 0.88 \\
\hline & & & Other & $2.2(-9.2,14)$ & 0.71 \\
\hline & & & LOS & $-0.43(-1.1,0.21)$ & 0.18 \\
\hline & & & Preop physical function & $-0.45(-0.74,-0.17)$ & 0.002 \\
\hline \multicolumn{6}{|c|}{ Change in sleep disturbance } \\
\hline Intercept & $-6.9(-9.2,-4.7)$ & & & $31(18,43)$ & \\
\hline Persistent & $3.7(-0.85,8.2)$ & 0.11 & & $4.2(-0.44,8.9)$ & 0.075 \\
\hline \multirow[t]{6}{*}{ Postop developed } & $7.0(-0.14,14)$ & 0.055 & & $3.3(-3.4,9.9)$ & 0.33 \\
\hline & & & Surgical approach & & \\
\hline & & & Posterior & $-0.77(-5.7,4.2)$ & 0.76 \\
\hline & & & Other & $-0.78(-13,12)$ & 0.90 \\
\hline & & & LOS & $-0.27(-0.96,0.42)$ & 0.44 \\
\hline & & & Preop sleep disturbance & $-0.62(-0.82,-0.42)$ & $<0.001$ \\
\hline \multicolumn{6}{|c|}{ Change in social satisfaction } \\
\hline Intercept & $9.6(7.4,12)$ & & & $35(19,51)$ & \\
\hline Persistent & $-5.1(-9.4,-0.73)$ & 0.02 & & $-7.0(-13,-1.5)$ & 0.01 \\
\hline \multirow[t]{6}{*}{ Postop developed } & $-8.0(-15,-1.1)$ & 0.02 & & $-8.1(-16,-0.44)$ & 0.04 \\
\hline & & & Surgical approach & & \\
\hline & & & Posterior & $-0.65(-6.6,5.3)$ & 0.83 \\
\hline & & & Other & $5.6(-8.7,20)$ & 0.44 \\
\hline & & & LOS & $-0.47(-1.3,0.35)$ & 0.26 \\
\hline & & & Preop social satisfaction & $-0.59(-0.94,-0.24)$ & 0.001 \\
\hline
\end{tabular}

${ }^{*}$ For categorical variables in linear regression models, one level of the variable is selected as a base level to determine the intercept coefficient. The remaining regression coefficients are then calculated for the remaining levels of the variable. Thus, for the categorical variables presented here, the first level of the variable, as presented in Table 1, is not listed in this table and is instead used as the base variable to calculate the intercept coefficient. The variable is considered significantly associated with the outcome if the regression coefficients for the remaining levels demonstrate significant $p$ values. For continuous variables in linear regression models, the coefficient represents the effect that a 1-point increase in the covariate would have on the outcome variable. The variable is considered significantly associated with the outcome if the regression coefficients for the remaining levels demonstrate significant $p$ values.

t The covariates selected, in addition to the depression/anxiety status change subgroups, are variables that were determined to be possible confounders because of significant difference between the subgroups (determined by ANOVA or Fisher's testing in Table 1) and were significantly associated with the outcome variables-the changes in PROMIS scores (determined by univariate regression on the outcomes in Table 4).

anxiety experienced improvement in these conditions after surgery. However, $15 \%$ of patients with no preoperative depression developed postoperative depression, and $7 \%$ of patients with no preoperative anxiety developed postoperative anxiety. Our results are similar to those of the previously mentioned study analyzing perioperative changes in depression in patients with degenerative lumbar conditions that found that $65 \%$ of patients with preoperative depression improved postoperatively. ${ }^{4}$

Although we identified an association between perioperative change in depression and anxiety and improvement in PROMIS scores, this study cannot confirm causation.
It is possible that the spine surgery itself plays a role in alleviating or worsening depression and anxiety; patients whose depression/anxiety improved may have presented with preoperative psychological symptoms caused by their spine conditions, whereas those who developed psychological symptoms after surgery may have done so because of adverse surgical sequelae or physical limitations during the recovery process. Such causation has been described by at least one study, which found microdiscectomy to improve pain-associated depression and somatic anxiety. ${ }^{8} \mathrm{~A}$ 2-year longitudinal study of patients who underwent lumbar surgery found that depression and anxiety symptoms 
Depression Subgroups Compared to Postoperatively Improved Depression Subgroup

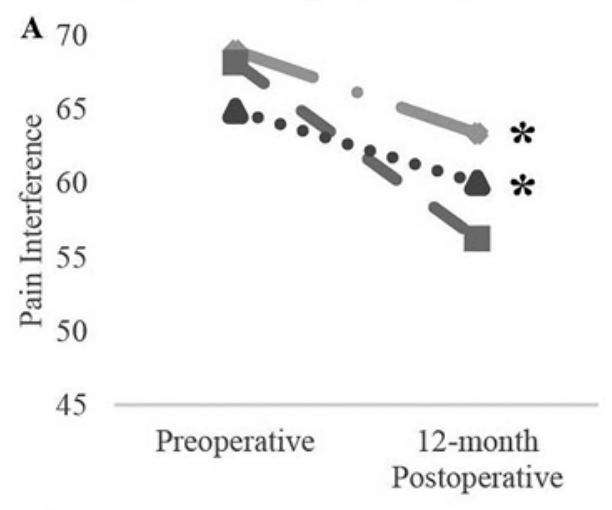

B 50
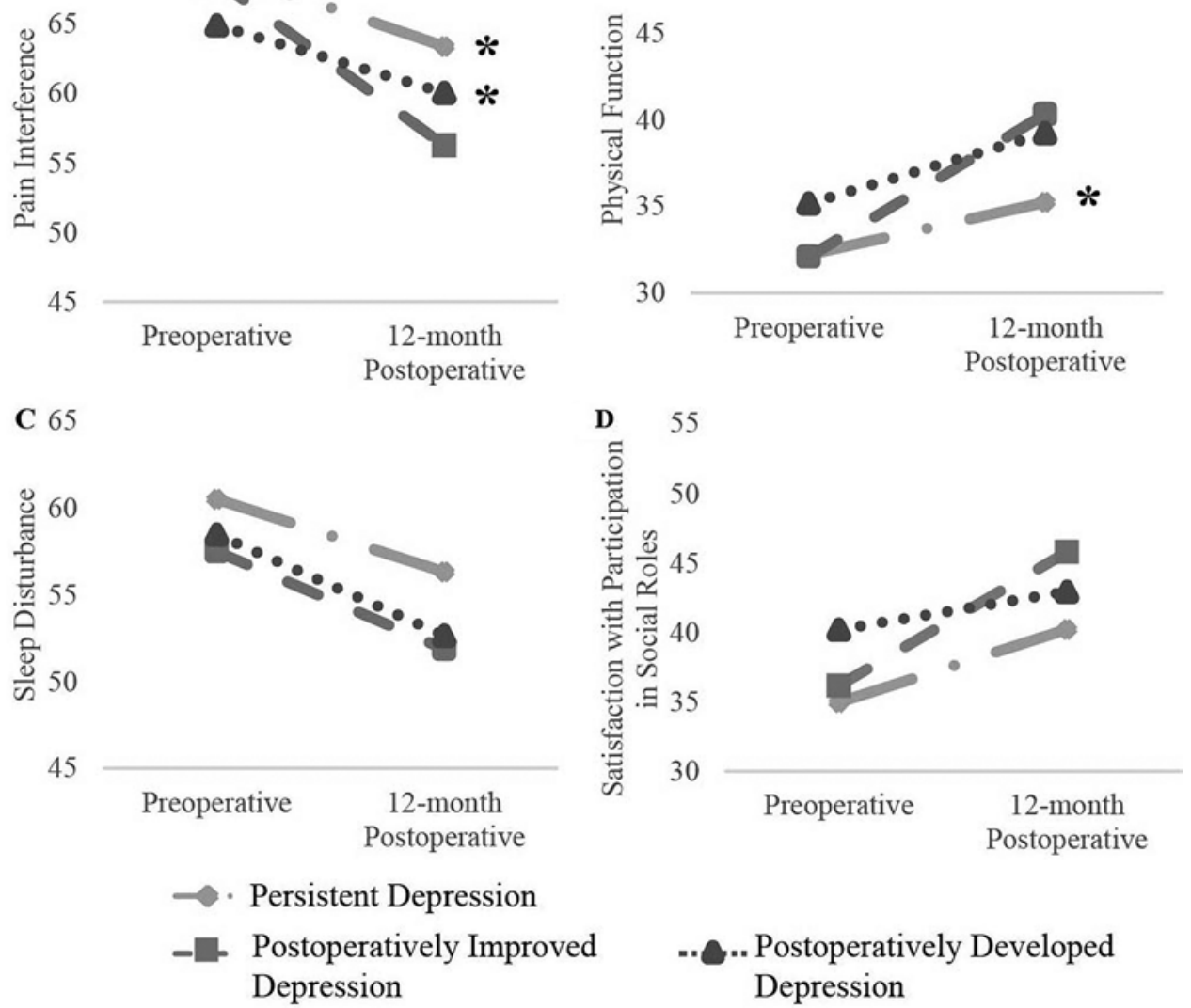

FIG. 4. Comparison of changes in preoperative and 12-month postoperative PROMIS scores between depression-change subgroups, compared with the postoperatively improved depression subgroup. Preoperative and 12-month postoperative line markers indicate the observed mean PROMIS scores for each depression subgroup. All groups of patients with different perioperative depression-change patterns experienced improvement in each of the 4 outcomes postoperatively. However, these groups differed significantly in the degree of improvement. Asterisks indicate significant differences between each subgroup and the postoperatively improved depression subgroup with regard to preoperative to 12-month postoperative changes in PROMIS score after adjusting for confounders (surgical approach, LOS, and the preoperative score for the PROMIS domain being measured) via multiple linear regression. A: For the PROMIS pain interference domain, the following patients had significantly less improvement compared with patients with postoperatively improved depression: patients with persistent depression had less improvement by 8.4 points $(95 \% \mathrm{Cl} 2.7,14)$, and patients with postoperatively developed depression had less improvement by 6.9 points $(95 \% \mathrm{Cl}$ 1.1, 13). B: For the PROMIS physical function domain, patients with persistent depression had less improvement by 6.3 points $(95 \% \mathrm{Cl} 1.6,11)$. C and D: For the PROMIS sleep disturbance and social satisfaction domains, respectively, patients did not have significantly better or worse improvement in scores compared with those of patients whose depression improved postoperatively.

improved significantly for patients who experienced more fulfillment of preoperative expectations, more improvement in Oswestry Disability Index values, and more improvement in pain. ${ }^{9}$ Alternatively, it is possible that the change in depression or anxiety itself causes the changes in PROs, since these were measured by values reported by the patients.

Many patients in our cohort reported symptoms of psychological distress before undergoing spine surgery, with $24 \%$ having some level of depression and $46 \%$ having some level of anxiety. Studies have reported rates of $29 \%-54 \%$ for preoperative depression in spine surgery patients. ${ }^{4,9,13} \mathrm{~A}$ previous study at our institution found that $24 \%$ of spine surgery patients had probable major depression, ${ }^{13}$ with this prevalence similar to the findings in our study. Studies have reported that $55 \%-59 \%$ of spine surgery patients have preoperative anxiety, which is slightly higher than our findings. ${ }^{9,13}$ Furthermore, an epidemiological study analyzing patients who underwent spinal fusion or laminectomy between 1990 and 2007 reported that depression and anxiety prevalence increased significantly in the study population over time..$^{2}$ Our findings and those of recent studies thus highlight the high prevalence of psychological distress in spine surgery patients and the importance of diagnosing and treating these conditions.

Given the difference in PROs between patients with preoperative psychological distress that improved compared with those with psychological distress that persisted, we compared characteristics between these 2 groups. The only significant difference was that patients whose depres- 
Anxiety Subgroups Compared to No Anxiety Subgroup

A
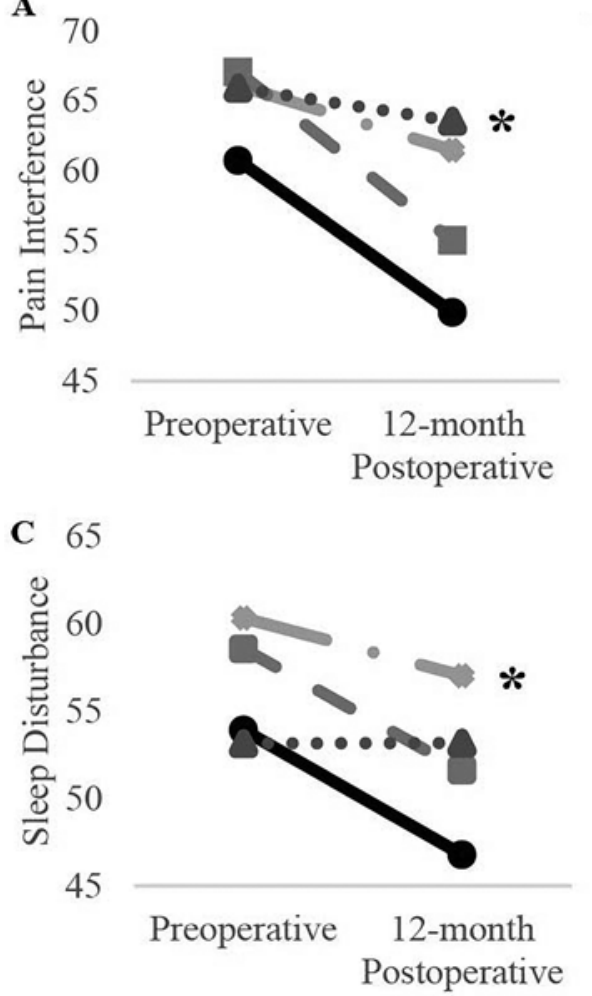

- No Anxiety

- Postoperatively Improved Anxiety
B

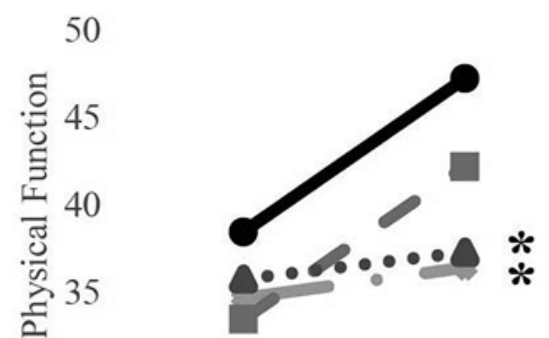

30

Preoperative 12-month

Postoperative

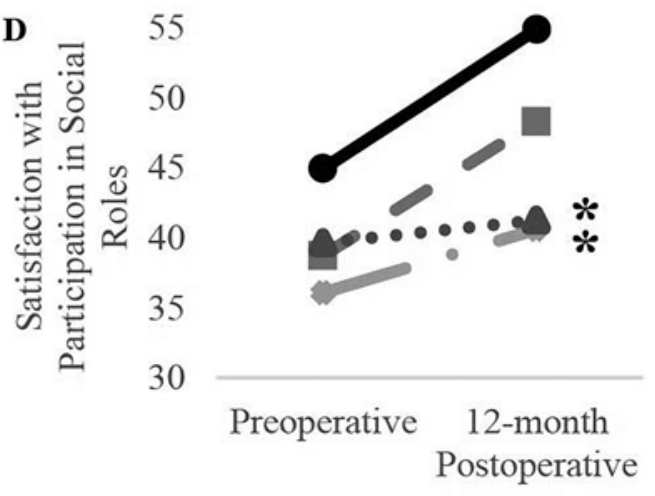

FIG. 5. Comparison of changes in preoperative and 12-month postoperative PROMIS scores between anxiety-change subgroups, compared with the no-anxiety subgroup. Preoperative and 12-month postoperative line markers indicate the observed mean PROMIS scores for each anxiety subgroup. All groups of patients with different perioperative anxiety-change patterns experienced improvement in each of the 4 outcomes postoperatively, with the exception of patients with postoperatively developed anxiety, who experienced worse sleep disturbance. However, these groups differed significantly in the degree of improvement. Asterisks indicate significant differences between each subgroup and the no-anxiety subgroup with regard to preoperative to 12-month postoperative changes in PROMIS scores after adjusting for confounders (surgical approach, LOS, and preoperative score for the PROMIS domain being measured) via multiple linear regression. A: For the PROMIS pain interference domain, the following patients had significantly less improvement compared with patients with no anxiety: patients with postoperatively developed anxiety by 9.7 points $(95 \% \mathrm{Cl} 2.1,17)$. B: For the PROMIS physical function domain, patients with persistent anxiety had less improvement by 7.1 points $(95 \% \mathrm{Cl} 3.1,11)$, and patients with postoperatively developed anxiety had less improvement by 7.4 points $(95 \% \mathrm{Cl} 1.7$, 13). C: For the PROMIS sleep disturbance domain, patients with persistent anxiety had less improvement by 6.3 points $(95 \% \mathrm{Cl}$ 1.3, 11). D: For the PROMIS social satisfaction domain, patients with persistent anxiety had less improvement by 8.1 points $(95 \%$ $\mathrm{Cl} 2.4,14)$, and patients with postoperatively developed anxiety had less improvement by 9.7 points $(95 \% \mathrm{Cl} 2.0,17)$.

sion persisted were more likely to have annual household income $<\$ 50,000$ compared with those whose depression improved. Given the lack of other preoperative differences between the groups, and given the significant differences in changes in PROs, this supports the theory that a surgical benefit may have caused the improvements in depression/ anxiety. Nonetheless, demographic characteristics should be further explored to help predict changes in depression/ anxiety after surgery.

The strengths of the present study include its large sample size with follow-up of 12 months. We included patients who underwent various types of spine surgery, making our findings generalizable to a wide range of spine surgery patients. We identified and adjusted for many potential confounders, including demographic parameters, surgeryassociated factors, and preoperative PROMIS scores, allowing us to analyze associations between psychological distress and PROs independently. Data on PROs were collected using PROMIS, allowing for consistency in interpreting scores across domains.

The limitations of the study include using PROMIS data as a measure of depression and anxiety. PROMIS does not use formal Diagnostic and Statistical Manual of Mental Disorders, 5th Edition, criteria or formal psychological surveys, such as the Beck Depression Inventory, to diagnose depression and anxiety. Instead, we treated de- 


\section{Anxiety Subgroups Compared to Postoperatively Improved Anxiety Subgroup}

A

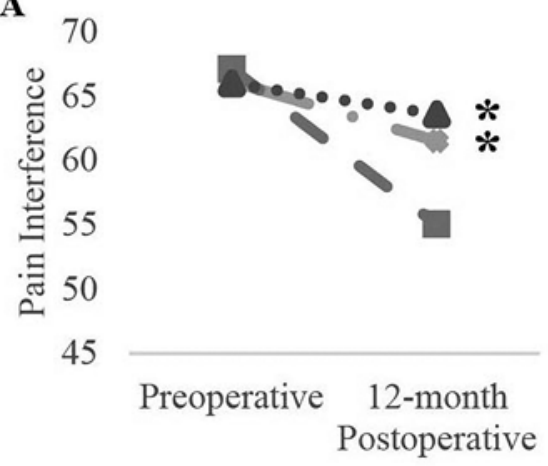

C

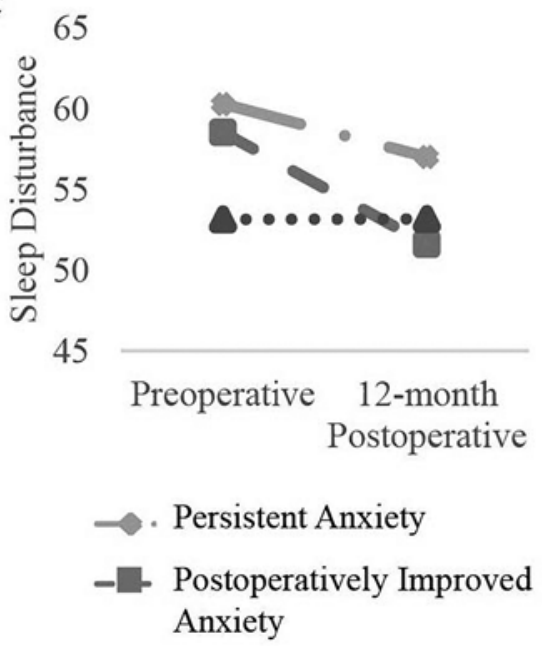

B
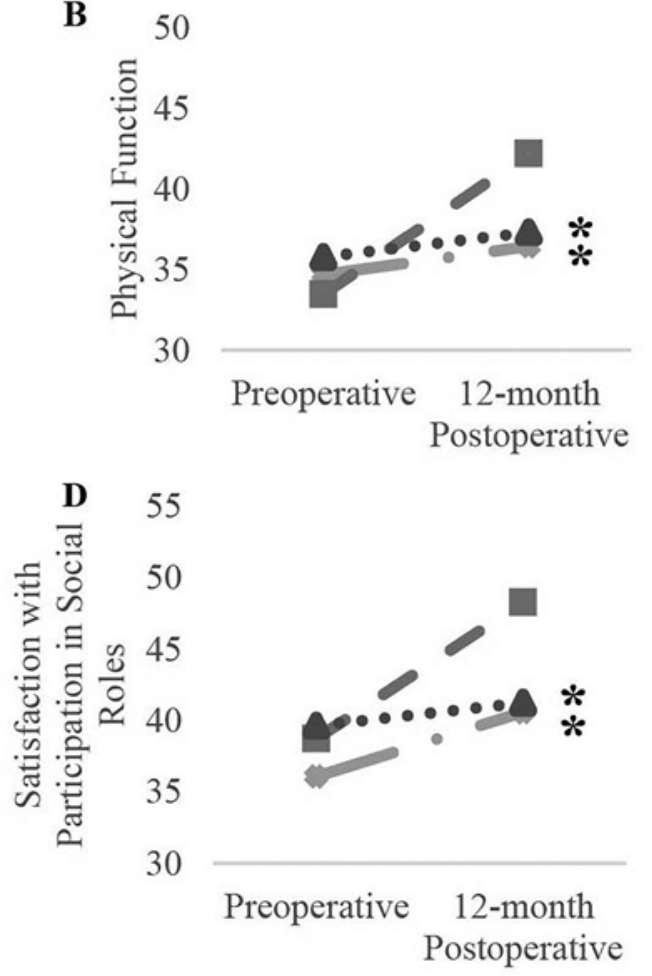

.... Postoperatively Developed Anxiety

FIG. 6. Comparison of changes in preoperative and 12-month postoperative PROMIS scores between anxiety-change subgroups, compared with postoperatively improved anxiety subgroup. Preoperative and 12-month postoperative line markers indicate the observed mean PROMIS scores for each anxiety subgroup. All groups of patients with different perioperative anxiety-change patterns experienced improvement in each of the 4 outcomes postoperatively, with the exception of patients with postoperatively developed anxiety, who experienced worse sleep disturbance. However, these groups differed significantly in the degree of improvement. Asterisks indicate significant differences between each subgroup and the postoperatively improved anxiety subgroup with regard to preoperative to 12-month postoperative changes in PROMIS scores after adjusting for confounders (surgical approach, LOS, and preoperative score for the PROMIS domain being measured) via multiple linear regression. A: For the PROMIS pain interference domain, the following patients had significantly less improvement compared with patients with postoperatively improved anxiety: patients with persistent anxiety had less improvement by 6.6 points $(95 \% \mathrm{Cl} 0.90,12)$, and patients with postoperatively developed anxiety had less improvement by 11 points $(95 \% \mathrm{Cl} 2.7,19)$. B: For the PROMIS physical function domain, patients with persistent anxiety had less improvement by 7.6 points $(95 \% \mathrm{CI} 3.3,12)$, and patients with postoperatively developed anxiety had less improvement by 7.5 points $(95 \% \mathrm{CI} 1.5,14)$. C: For the PROMIS sleep disturbance domain, patients did not have significantly better or worse improvement in scores compared with those whose anxiety postoperatively improved. D: For the PROMIS social satisfaction domain, patients with persistent anxiety had less improvement by 7.0 points $(95 \% \mathrm{Cl} 1.5,13)$, and patients with postoperatively developed anxiety had less improvement by 8.1 points $(95 \% \mathrm{Cl} 0.4,16)$.

pression and anxiety as continuums based on the continuous PROMIS scoring system, and we used criteria defined by the American Psychiatric Association to label mild, moderate, and severe instances of each condition.

This study highlights the need to assess and treat psychological distress in spine surgery patients to maximize PROs. Further research is needed to determine how best to distinguish between patients whose depression and anxiety improve and those whose depression and anxiety persist postoperatively, because these different psychological distress progressions have different implications for PRO improvement. Further work should explore the causal re- lationship between psychological distress and PRO improvement.

\section{Conclusions}

Many patients have depression or anxiety before undergoing spine surgery, and for many patients, depression and anxiety are alleviated after surgery. However, patients whose depression/anxiety persists and those who have new-onset depression/anxiety after surgery have less improvement in 12-month PROMIS scores than do patients who have no depression or anxiety before or after 
surgery and those whose depression/anxiety improves after surgery. Postoperative changes in depression/anxiety may thus have a greater effect than preoperative depression/anxiety on changes in PROs after spine surgery. These findings suggest a need to address the mental health of spine surgery patients because doing so may improve PROs.

\section{References}

1. Adogwa O, Carr K, Fatemi P, Verla T, Gazcon G, Gottfried $\mathrm{O}$, et al: Psychosocial factors and surgical outcomes: are elderly depressed patients less satisfied with surgery? Spine (Phila Pa 1976) 39:1614-1619, 2014

2. American Psychiatric Association: Online assessment measures. Psychology.org (https://www.psychiatry.org/ psychiatrists/practice/dsm/educational-resources/assessmentmeasures) [Accessed December 13, 2019]

3. Bierke S, Petersen W: Influence of anxiety and pain catastrophizing on the course of pain within the first year after uncomplicated total knee replacement: a prospective study. Arch Orthop Trauma Surg 137:1735-1742, 2017

4. Falavigna A, Righesso O, Teles AR, Conzati LP, Bossardi JB, da Silva PG, et al: Responsiveness of depression and its influence on surgical outcomes of lumbar degenerative diseases. Eur J Orthop Surg Traumatol 25 (Suppl 1):S35-S41, 2015

5. Greenland S, Pearl J, Robins JM: Causal diagrams for epidemiologic research. Epidemiology 10:37-48, 1999

6. HealthMeasures: Intro to PROMIS. HealthMeasures. net (http://www.healthmeasures.net/explore-measurementsystems/promis/intro-to-promis) [Accessed December 13, 2019]

7. Järvimäki V, Kautiainen H, Haanpää M, Koponen H, Spalding M, Alahuhta $\mathrm{S}$, et al: Depressive symptoms are associated with poor outcome for lumbar spine surgery. Scand J Pain 12:13-17, 2016

8. Lebow R, Parker SL, Adogwa O, Reig A, Cheng J, Bydon A, et al: Microdiscectomy improves pain-associated depression, somatic anxiety, and mental well-being in patients with herniated lumbar disc. Neurosurgery 70:306-311, 2012

9. Mancuso CA, Duculan R, Cammisa FP, Sama AA, Hughes AP, Lebl DR, et al: Successful lumbar surgery results in improved psychological well-being: a longitudinal assessment of depressive and anxiety symptoms. Spine J 18:606-613, 2018

10. Martin RL, Christoforetti JJ, McGovern R, Kivlan BR, Wolff AB, Nho SJ, et al: The impact of depression on patient outcomes in hip arthroscopic surgery. Orthop J Sports Med 6:2325967118806490, 2018
11. McNamee R: Confounding and confounders. Occup Environ Med 60:227-234, 164, 234, 2003

12. Menendez ME, Neuhaus V, Bot AG, Ring D, Cha TD: Psychiatric disorders and major spine surgery: epidemiology and perioperative outcomes. Spine (Phila Pa 1976) 39:E111E122, 2014

13. Purvis TE, Neuman BJ, Riley LH, Skolasky RL: Comparison of PROMIS Anxiety and Depression, PHQ-8, and GAD-7 to screen for anxiety and depression among patients presenting for spine surgery. J Neurosurg Spine 30:524-531, 2019

14. Steyerberg EW: Clinical Prediction Models: A Practical Approach to Development, Validation, and Updating, ed 2. Cham, Switzerland: Springer Nature, 2019

\section{Disclosures}

Dr. Sciubba reports that he consults for the following: Medtronic, DePuy Synthes, Stryker, NuVasive, Baxter, K2M, and Globus. Dr. Neuman reports receipt of non-study-related clinical or research efforts that he oversees from DePuy Synthes; he also reports being a speaker for Medtronic.

\section{Author Contributions}

Conception and design: Rahman, Neuman. Acquisition of data: Skolasky, Riley, Cohen, Sciubba, Kebaish, Neuman. Analysis and interpretation of data: Rahman, Ibaseta, Reidler, Andrade. Critically revising the article: Rahman, Ibaseta, Reidler, Andrade. Reviewed submitted version of manuscript: Rahman, Ibaseta, Reidler, Andrade, Skolasky, Riley, Cohen, Sciubba, Kebaish, Neuman. Approved the final version of the manuscript on behalf of all authors: Neuman. Statistical analysis: Rahman, Ibaseta, Reidler, Andrade, Skolasky. Administrative/technical/material support: Skolasky. Study supervision: Neuman.

\section{Supplemental Information}

Online-Only Content

Supplemental material is available with the online version of the article.

Supplementary Table. https://thejns.org/doi/suppl/10.3171/ 2019.11.SPINE19586.

\section{Correspondence}

Brian J. Neuman: The Johns Hopkins University School of Medicine, Baltimore, MD. bneuman7@jhmi.edu. 